\title{
THE TRANSPORTER-LIKE PROTEIN INEBRIATED MEDIATES HYPEROSMOTIC STIMULI THROUGH INTRACELLULAR SIGNALING
}

\author{
CHI-SUNG CHIU ${ }^{1,4}$, LINDA S. ROSS ${ }^{2}$, BRUCE N. COHEN ${ }^{3}$, HENRY A. LESTER ${ }^{4}$ AND SARJEET S. GILL ${ }^{1,2, *}$ \\ ${ }^{1}$ Graduate Program in Environmental Toxicology, ${ }^{2}$ Department of Cell Biology and Neuroscience and \\ ${ }^{3}$ Division of Biomedical Science, University of California, Riverside, CA 92521, USA and \\ ${ }^{4}$ Division of Biology, California Institute of Technology, Pasadena, CA 91125, USA \\ *Author for correspondence (e-mail: Sarjeet.Gill@ucr.edu)
}

Accepted 7 September; published on WWW 2 November 2000

\begin{abstract}
Summary
We cloned the inebriated homologue MasIne from Manduca sexta and expressed it in Xenopus laevis oocytes. MasIne is homologous to neurotransmitter transporters but no transport was observed with a number of putative substrates. Oocytes expressing MasIne respond to hyperosmotic stimulation by releasing intracellular $\mathrm{Ca}^{2+}$, as revealed by activation of the endogenous $\mathrm{Ca}^{2+}$-activated $\mathrm{Cl}^{-}$current. This $\mathrm{Ca}^{2+}$ release requires the $\mathrm{N}$-terminal 108 amino acid residues of MasIne and occurs via the inositol trisphosphate pathway. Fusion of the $\mathbf{N}$ terminus to the rat $\gamma$-aminobutyric acid transporter (rGAT1) also renders rGAT1 responsive to hyperosmotic stimulation.

Immunohistochemical analyses show that MasIne and Drosophila Ine have similar tissue distribution patterns, suggesting functional identity. Inebriated is expressed in tissues and cells actively involved in $\mathrm{K}^{+}$transport, which suggests that it may have a role in ion transport, particularly of $\mathrm{K}^{+}$. We propose that stimulation of MasIne releases intracellular $\mathrm{Ca}^{2+}$ in native tissues, activating $\mathrm{Ca}^{2+}$-dependent $\mathrm{K}^{+}$channels, and leading to $\mathrm{K}^{+}$transport.

Key words: Manduca sexta, inebriated, $\mathrm{Ca}^{2+}$-activated $\mathrm{Cl}^{-}$current, inositol trisphosphate, permeable phospholipase C.
\end{abstract}

\section{Introduction}

The $\mathrm{Na}^{+} / \mathrm{Cl}^{-}$-dependent neurotransmitter transporter (NTT) superfamily consists of proteins that transport neurotransmitters $[\gamma$-aminobutyric acid (GABA), serotonin, dopamine, norepinephrine, epinephrine, glycine, proline], osmolytes (taurine, betaine) and metabolites (creatine) (Shafqat et al., 1993). Ligand transport is driven by a $\mathrm{Na}^{+}$ concentration gradient. All the proteins in this superfamily have 12 putative transmembrane regions (TMs) with cytoplasmic $\mathrm{N}$ and $\mathrm{C}$ termini, a predicted large extracellular loop between TM3 and TM4, and 109 conserved amino acid residues (Shafqat et al., 1993). Neurotransmitter transporters are expressed in the synaptic region and terminate neurotransmission by active reuptake of neurotransmitters.

Drosophila inebriated (Ine) and RosA are 'orphan transporters' with no known function. These two gene products have the same putative topology as members of the NTT superfamily but share only $36-41 \%$ amino acid identity with them (Soehnge et al., 1996; Burg et al., 1996). Drosophila ine mutants show no behavioral defects. At the neuromuscular junction of these mutants, brief high-frequency nerve stimulation in the presence of quinidine, a $\mathrm{K}^{+}$channel inhibitor, evokes abnormal repetitive neuronal firing and an increase in transmitter release, thus increasing the excitatory junction potential amplitude. Double mutants of ine and shaker, a $\mathrm{K}^{+}$channel, or ine and hyperkinetic (HK), a beta subunit of shaker, exhibit a 'down-turned wings and indented thorax' phenotype with behavioral defects (uncoordination and flightlessness) (Stern and Ganetzky, 1992). This phenotype is also observed in shaker mutants carrying either an additional mutation in the ether-a-go-go (eag) $\mathrm{K}^{+}$channel or overexpressing a $\mathrm{Na}^{+}$channel gene, para (Ganetzky and $\mathrm{Wu}$, 1983; Stern et al., 1990). The shaker:eag double-mutant phenotype is apparently caused by the elimination of two types of $\mathrm{K}^{+}$channel that are partially redundant. The observation that the shaker:ine double mutant also gave a similar phenotype led Stern and Ganetzky (1992) to suggest that Ine also modulates ion conductance, especially of $\mathrm{K}^{+}$. However, elucidation of the ine sequence showed that it encodes a protein related to the NTT superfamily. Thus, Soehnge et al. (1996) proposed that Ine is either a GABA or glutamate transporter because these neurotransmitters are common in insect neuromuscular junctions.

In an effort to identify neurotransmitter transporters in the tobacco hornworm Manduca sexta, we cloned a cDNA that encodes a protein, MasIne, which has $55 \%$ amino acid identity with Ine and RosA proteins from Drosophila. MasIne and Ine have similar tissue distributions, suggesting a functional identity between the two proteins. We also demonstrate that, in Xenopus oocytes, MasIne responds to hyperosmotic 
stimulation by activating the phospholipase C (PLC) and inositol trisphosphate $\left(\mathrm{InsP}_{3}\right)$ signaling cascade, which in turn activates $\mathrm{Ca}^{2+}$-activated $\mathrm{Cl}^{-}$currents in these oocytes. PLC activation is mediated by the $\mathrm{N}$ terminus of MasIne. The ability of a transporter protein to activate intracellular signaling suggests that these proteins may have more diverse functions than previously believed.

\section{Materials and methods \\ Isolation of MasIne cDNA}

Total RNA was isolated from 3-day-old eggs of Manduca sexta and from the brain and ventral nerve cord of 2- to 4-dayold fifth-instar larvae as described by Mbungu et al. (1995). Reverse transcription/polymerase chain reaction (RT-PCR) was performed using degenerate primers complementary to conserved sequences of mammalian dopamine, GABA, serotonin and norepinephrine transporters. The forward primer was 5'-CGGAATTCTGG(G/C)CAA(T/C)(G/A)TIT$\mathrm{GG}(\mathrm{A} / \mathrm{C}) \mathrm{GITT}(\mathrm{C} / \mathrm{T}) \mathrm{CCNTA}$, and the reverse primer was 5'-GCCAAGCTTGAAGAAGAT(C/T)TG(G/A)GIIGCIGC(G/ A)TCNA $(\mathrm{C} / \mathrm{T} / \mathrm{G}) \mathrm{CCA}$. Products of $0.7 \mathrm{~kb}$ were obtained, and these were cloned and sequenced.

Isolation of full-length MasIne cDNA was achieved by PCR screening as described by Ross and Gill (1996) using an embryonic size-selected cDNA library in pSPORT1 (Mbungu et al., 1995). A MasIne-specific primer, 5'-GGTACCGGTCCGGAATTCCCGGG, and a pSPORT1-vector-specific primer were used. Both strands of the cDNA clone were sequenced by dideoxy chain termination using Sequenase 2.0 (Amersham).

\section{Antibody generation}

Secondary structure analysis predicted that a putative extracellular loop between TM3 and TM4 (amino acid residues 277-320) and the $\mathrm{C}$ terminus (amino acid residues 685-725) would be highly antigenic regions. These regions were PCR-amplified using specific primers and Taq DNA polymerase (Life Science Technologies). The PCR products were then cloned in tandem into pQE30 (Qiagen) and sequenced to ensure that no mutations were introduced during PCR. The His-tag fusion peptide was expressed and then purified by Ni-NTA affinity chromatography followed by a preparative SDS-PAGE gel. The purified peptide was used for rabbit immunization. MasIne-specific IgG was affinitypurified using an SDS-PAGE-purified fusion peptide (Pringle et al., 1991).

\section{Immunoprecipitation and western blot analysis}

Immunoprecipitation was performed following published protocols (Bruss et al., 1995; Pralong-Zamofing et al., 1992). Tissues and oocytes were homogenized in buffer A (250 $\mathrm{mmol}^{-1}$ sucrose, $1 \mathrm{mmol}^{-1}$ EDTA, pH 8.0, $10 \mathrm{mmoll}^{-1}$ Tris-HCl, $\mathrm{pH} 7.5$ ) containing $0.5 \mathrm{mmol}^{-1}$ phenylmethylsulfonyl fluoride (PMSF) and $5 \mu \mathrm{g} \mathrm{ml}^{-1}$ each of pepstatin and leupeptin. The homogenates were centrifuged at $1000 \mathrm{~g}$ for $10 \mathrm{~min}$, and the supernatant then centrifuged at $100000 \mathrm{~g}$ for $30 \mathrm{~min}$. The resulting pellet was resuspended in buffer consisting of $150 \mathrm{mmol}^{-1} \mathrm{NaCl}, 1 \mathrm{mmol}^{-1}$ EDTA, pH 8.0, $250 \mathrm{mmol}^{-1}$ PMSF, $0.1 \%$ SDS (w/v), $1 \%$ Triton X-100 (v/v), $1 \%$ sodium deoxycholate, $10 \mathrm{mmoll}^{-1}$ Tris- $\mathrm{HCl}, \mathrm{pH} 7.4$ and $5 \mu \mathrm{g} \mathrm{ml}^{-1}$ of leupeptin and aprotinin, and then centrifuged at $10000 \mathrm{~g}$ for $20 \mathrm{~min}$. The supernatants $(8 \mathrm{ml})$ were mixed with $1.5 \mu \mathrm{g}$ of the affinity-purified MasIne-specific IgG and incubated at $4{ }^{\circ} \mathrm{C}$ overnight. Protein A-Sepharose CL-4B gel $(50 \% \mathrm{v} / \mathrm{v}$; $15 \mu \mathrm{l})$ was added, and the mixture was incubated for a further $4 \mathrm{~h}$ at $4{ }^{\circ} \mathrm{C}$. After a brief centrifugation, the pellet was washed in the following three solutions: Tween 20/urea buffer (100 mmol $^{-1}$ Tris-HCl, pH 7.5, $200 \mathrm{mmol} \mathrm{l}^{-1} \mathrm{NaCl}, 2 \mathrm{moll}^{-1}$ urea, $0.5 \%$ Tween 20$)$, Tween 20 buffer $\left(50 \mathrm{mmoll}^{-1}\right.$ Tris$\mathrm{HCl}, \mathrm{pH} 7.5,150 \mathrm{mmol}^{-1} \mathrm{NaCl}, 0.5 \%$ Tween $20,1 \mathrm{mmol}^{-1}$ EDTA) and TBS buffer (the Tween 20 buffer without Tween). Following these washes, the Sepharose gel was resuspended in $2 \times$ SDS sample buffer and separated on a $10 \%$ gel using SDS-PAGE. The proteins were then transferred electrophoretically $(0.5 \mathrm{~A}$ for $1.5 \mathrm{~h})$ to an Immobilon $\mathrm{P}$ membrane (Millipore). Western blot analysis was performed using MasIne-specific $\operatorname{IgG}$ as the primary antibody and goat anti-rabbit IgG conjugated with alkaline phosphatase as the secondary antibody. The membrane was then stained with 5-bromo-4-chloro-3-indolyl phosphate/ nitro blue tetrazolium (BCIP/NBT) (Sigma). For experiments using $\left[{ }^{35} \mathrm{~S}\right]$ methionine-labeled oocytes, the membranes were exposed to intensifying screens (Kodak).

\section{Immunohistochemistry}

Tissues and oocytes were fixed overnight in alcoholic Bouin's fixative, dehydrated in stages through 70-100\% ethanol and 30-100\% xylene, and infiltrated and embedded in paraffin wax. Sections $(7-10 \mu \mathrm{m})$ on silane-coated slides were dried at $40^{\circ} \mathrm{C}$, washed with xylene and rehydrated in a graded ethanol series. To expose MasIne, the sections were boiled (twice, $10 \mathrm{~min}$ each) in $10 \mathrm{mmoll}^{-1}$ sodium citrate (pH6.0), washed with phosphate-buffered saline (PBS) and blocked in PBS containing 2\% normal goat serum (NGS) (blocking buffer) for $1 \mathrm{~h}$. The sections were incubated overnight in a humidified chamber at $4{ }^{\circ} \mathrm{C}$ with affinity-purified MasInespecific $\mathrm{IgG}$ in blocking buffer.

For fluorescence immunohistochemistry, goat anti-rabbit Cy3-conjugated IgG (Jackson Immuno Research) was used as the secondary antibody. Following five washes in PBS with $0.1 \%$ Triton X-100, the secondary antibody (diluted 1:200 in PBS) was added and incubated at room temperature $\left(26^{\circ} \mathrm{C}\right)$ for $60 \mathrm{~min}$. The slides were then washed sequentially with the Tween 20/urea, Tween 20 and TBS buffers described above. The sections were mounted with mounting medium (Vector) and analyzed using fluorescence microscopy.

For alkaline phosphatase staining, the secondary antibody, goat anti-rabbit IgG conjugated to alkaline phosphatase (Jackson Immuno Research), was diluted 1:200 in blocking buffer. After a $5 \mathrm{~h}$ incubation at room temperature, the slides were washed twice with PBS, once with PBS containing 
$0.05 \%$ Triton-X100, and then twice with PBS. They were then incubated for $20 \mathrm{~min}$ in substrate solution $(20 \mu \mathrm{l}$ of naphthol AS-MX phosphate, $35 \mathrm{mg} \mathrm{ml}^{-1}$ in dimethyl formamide, and $10 \mathrm{ml}$ of filtered Fast Red Violet LB salt, $0.2 \mathrm{mg} \mathrm{ml}^{-1}$ in $0.1 \mathrm{moll}^{-1}$ Tris-Cl, $\mathrm{pH} 8.5$, prepared and mixed just before use). Color development, monitored by light microscopy, was stopped with Tris-Cl buffer, $\mathrm{pH} 8.5$. The slides were sealed in 2 parts $10 \%$ gelatin: 1 part glycerol (Zitnan et al., 1999) and kept at $-20^{\circ} \mathrm{C}$ until visualized by light microscopy.

\section{MasIne expression in Xenopus oocytes}

The MasIne open reading frame (ORF) was cloned into pBS KS+ AMV-PA50 (pAMV) (Nowak et al., 1998) containing an alfalfa mosaic virus RNA $5^{\prime}$-untranslated region (UTR), which enhances protein expression (Jobling and Gehrke, 1987). A 98 bp bovine preprolactin 3'-UTR, which stabilizes cRNA in Xenopus oocytes (Vassilakos et al., 1995), was synthesized by PCR and cloned upstream of the poly(A) tail. Two MasIne constructs using either base pair 135 or base pair 459 as the start site and base pair 2318 as the stop site were made using PCR (Expand High Fidelity PCR System, Boehringer Mannheim). The second amino acid residue of MasIne-135 was intentionally changed from asparagine to aspartic acid to introduce an NcoI site. To obtain the wild-type aspartic acid residue, a back mutation was made. DNA sequencing verified the final constructs.

The 108-rGAT1 construct was made by amplifying the AMV 5'-UTR and 135-458 bp of MasIne and cloning it in-frame with the rest of the wild-type rGAT (rat GABA transporter) into pAMV. Both $\triangle$ MasIne-135 and $\triangle$ MasIne-459 deletion constructs were made by $A c c \mathrm{I} / \mathrm{BamHI}$ restriction digestion, which deleted the fragment between base pairs 819 and 2285 for MasIne-135 and the corresponding region of MasIne-459. The restricted ends were blunt-ended with T4 DNA polymerase and religated. This deletion causes no reading frame shift. Thus, $\Delta$ MasIne- 135 has only the $\mathrm{N}$ terminal 228 residues and $\Delta$ MasIne-459 has only the $\mathrm{N}$ terminal 120 residues, respectively, and the C-terminal 10 amino acid residues; TM3-TM12 and most of the $\mathrm{C}$ terminus are deleted.

A sample of cRNA was obtained in vitro using the mMessage mMachine (Ambion) transcription kit. For expression, stage $\mathrm{V}$ or VI oocytes were injected with approximately $32 \mathrm{ng}$ of MasIne cRNA. Oocytes were incubated at $18{ }^{\circ} \mathrm{C}$ in either complete Barth's medium or in ND96 with 2\% horse serum. MasIne-135- and MasIne-459expressing oocytes were assayed after at least $96 \mathrm{~h}$ of incubation, and 108-rGAT1, $\Delta$ MasIne-135 and $\Delta$ MasIne-459 were assayed between 30 and $60 \mathrm{~h}$ of incubation. Ligand uptake assays were performed as described by Guastella et al. (1990). Expression of MasIne-135 and MasIne-459 was analyzed by incubating the injected oocytes (80-100 each) in medium containing $\left[{ }^{35} \mathrm{~S}\right]$ methionine $\left(37 \mathrm{MBq} \mathrm{ml}^{-1}\right)$ for $30 \mathrm{~h}$ (pulse) followed by incubation with medium containing cold methionine for an additional $42 \mathrm{~h}$ (chase); these oocytes were used for immunoprecipitation and western blot analysis.

\section{Electrophysiology}

The oocytes were voltage-clamped using a Dagan TEV 200 or a GeneClamp 500 (Axon Instruments, Inc.) voltage-clamp amplifier. Agar bridges $\left(3 \mathrm{moll}^{-1} \mathrm{KCl}\right)$ were used as reference electrodes. The microelectrodes were filled with $3 \mathrm{moll}^{-1} \mathrm{KCl}$ and had resistances of 1-2 $\mathrm{M} \Omega$. A DigiData 1200 (Axon Instruments, Inc.) A/D converter and pCLAMP 6.0 or 7.0 (Axon Instruments, Inc.) were used to record the data digitally. Analysis was performed using the Origin software (Microcal).

Oocytes in the recording chamber were exposed either to isotonic solution ( $100 \mathrm{mmoll}^{-1}$ Tris- $\mathrm{Cl}, 1 \mathrm{mmol}^{-1} \mathrm{MgCl}_{2}$ and 5 mmol $^{-1}$ Hepes, $\mathrm{pH} 7.4 ; 214$ mosmol $^{-1}$ ) or to hyperosmotic solutions (Tris-Cl isotonic solution plus different concentrations of sucrose). Oocytes expressing wild-type MasIne were first exposed to isotonic solution and then to hyperosmotic solution. For the ion-selectivity experiments, $\mathrm{Cl}^{-}$ was replaced by gluconate and Tris ${ }^{+}$was replaced by $\mathrm{Na}^{+}, \mathrm{Li}^{+}$ or $\mathrm{K}^{+}$.

To test for ligand-independent leakage currents, the membrane potential was held at $-60 \mathrm{mV}$ while oocytes were superfused with Tris-Cl isotonic solution and a background current was recorded. The solution was then changed either to ND96 or LiCl Ringer $\left(96 \mathrm{mmoll}^{-1} \mathrm{NaCl}\right.$ or $96 \mathrm{mmoll}^{-1} \mathrm{LiCl}$, $2 \mathrm{mmoll}^{-1} \mathrm{KCl}, 1 \mathrm{mmol} \mathrm{l}^{-1} \mathrm{MgCl}_{2}, 5 \mathrm{mmoll}^{-1}$ Hepes, $\mathrm{pH}$ 7.5) for 2-3 min, and the leakage current was recorded. To measure the ligand-independent $\mathrm{Na}^{+}$-coupled transient current, we used the $\mathrm{I}_{\mathrm{Cl}-1}$ voltage-step protocol (see below). Both rGAT1 and rSERT were used as positive controls.

To record $\mathrm{Ca}^{2+}$-activated $\mathrm{Cl}^{-}$currents, two different voltagestep protocols were applied to oocytes. To characterize the outwardly rectifying $\mathrm{Cl}^{-}$currents and to test for ligandindependent $\mathrm{Na}^{+}$-coupled transient current, a protocol named 'I $\mathrm{I}_{\mathrm{Cl}-1}$ voltage-step' was used. The membrane potential was held at $-40 \mathrm{mV}$ for $30 \mathrm{~ms}$, then stepped to test potentials between $+100 \mathrm{mV}$ and $-140 \mathrm{mV}$ in $-30 \mathrm{mV}$ increments for $195 \mathrm{~ms}$ and finally stepped back to $-40 \mathrm{mV}$ for $60 \mathrm{~ms}$ (Hartzell, 1996; Mager et al., 1993). To characterize inward $\mathrm{Cl}^{-}$currents, we used the 'I $\mathrm{Cl}-2$ voltage-step' protocol. The voltage was held at $-35 \mathrm{mV}$ for $50 \mathrm{~ms}$, stepped to $+20 \mathrm{mV}$ for $900 \mathrm{~ms}$, then stepped to test potentials between $+80 \mathrm{mV}$ and $-140 \mathrm{mV}$ in $-20 \mathrm{mV}$ increments for $900 \mathrm{~ms}$, and finally stepped back to $-35 \mathrm{mV}$ for 100 ms (Hartzell, 1996).

Stock solutions of niflumic acid, 5-nitro-2(3-phenylpropylamino) benzoic acid (NPPB), 1,2-bis(2-aminophenoxy)ethane$N, N, N, N$-tetra-acetic acid acetoxymethyl ester (BAPTA-AM), 1(6-\{[(17ß)-3-methoxyestra-1,3,5(10)-trien-17-yl]amino\}hexyl)1H-pyrrole-2,5-dione (U73122) and 1-(6-\{[(17ß)-3-methoxyestra-1,3,5(10)-trien-17-yl]amino \}hexyl)-2,5-pyrrolidine-dione (U73343) were prepared in dimethylsulfoxide (DMSO), while $\mathrm{LaCl}_{3}$, heparin, guanosine-5'-O-(2-thiodiphosphate) trilithium (GDP- $\beta-S$ ) and $\mathrm{K}_{4} \mathrm{BAPTA}$ (the potassium salt of BAPTA) were dissolved in water or buffer. 


\section{Results \\ Cloning and sequence analysis of MasIne}

The $4956 \mathrm{bp}$ full-length MasIne cDNA has two potential start codons, at base pairs 135 and 459, that fit the consensus Kozak sequence (Kozak, 1987) and a stop codon at base pair 2318. Thus, MasIne has two potential open reading frames encoding polypeptides of either 727 or 619 amino acid residues. TMPred analysis (http://www.ch.embnet.org/ software/TMPRED_form.html) suggests that MasIne has 12 transmembrane domains, as observed in other $\mathrm{Na}^{+} / \mathrm{Cl}^{-}$dependent neurotransmitter transporters, and a large extracellular loop between TM3 and TM4. Of the 109 amino acid residues conserved in most other neurotransmitter transporters, 91 are present in MasIne. This protein has $55 \%$ amino acid identity with Drosophila Ine and RosA (Fig. 1), but only $37 \%$ identity with Manduca GAT and 30-42\% identity with other neurotransmitter transporters. Dendogram analyses show that the Drosophila and Manduca inebriated proteins are divergent from the other neurotransmitter transporters (data not shown), suggesting that these proteins have a function distinct from that of other neurotransmitter transporters.

Tissue distribution of inebriated proteins in Manduca and Drosophila

Two major broad bands at 58-80 and 150-205 kDa were observed in immunoprecipitations of $M$. sexta fifth-instar day 1 midgut and day 1 whole larvae (Fig. 2). The $58-80 \mathrm{kDa}$ bands are of the size expected for the unglycosylated MasIne monomer. The $170-200 \mathrm{kDa}$ broad band is probably the glycosylated and oligomerized MasIne. Broad bands are expected because MasIne is a membrane protein, and two alternatively spliced homologues, Ine and RosA, have been identified in Drosophila. Similar broad bands were also observed in oocytes expressing MasIne (see Fig. 5D). These results show that the $\operatorname{IgG}$ for MasIne is specific for this protein.

In the central nervous system of Manduca sexta larvae, high levels of MasIne expression were observed in the glial cells, neuropil and axons in the connective and segmental nerves. No expression was detected in the neuronal perikarya (Fig. 3A,B). The preimmune serum showed no immunoreactivity with the brain (Fig. 3C), optic lobes (Fig. 4C) or any other tissue. In the larval midgut, MasIne expression was observed in the basolateral membrane of goblet cells (Fig. 3D,E). In larval Malpighian tubules, MasIne was expressed in the basolateral membrane of the proximal region and weakly expressed in the middle region (Fig. 3F). MasIne was also expressed in the basolateral membrane of the epithelial cells of the ileum, the rectum and the outer Malpighian tubules of the cryptonephridial system (Fig. 3G,H). In muscles, MasIne expression was detected in the T-tubules but not the myofibrils (Fig. 3I). In adult Manduca sexta optic lobes, MasIne was expressed in retinula cells (cell body and rhabdomere), optic nerve axons, lamina and projections to the medulla (Fig. 4A).

Part of the fusion peptide used to generate the antibodies, amino acid residues 277-320 of MasIne, has $63 \%$ identity with ine. We therefore tested the ability of the MasIne antibody to detect Ine expression in Drosophila melanogaster. The MasIne-specific IgG detected the Ine protein in adult Drosophila melanogaster in the optic lobes, muscle system and axon bundles. In the optic lobes, Ine expression was observed in the retinula, lamina and axonal projections to the medulla (Fig. 4B) with the same pattern as that observed in Manduca sexta. Ine was also expressed in neurons and axon bundle of the antennal chordotonal organs of Drosophila melanogaster (Fig. 4D), and in the T-tubules of the leg and dorsal longitudinal flight muscles (Fig. 4E). The MasIne antibody also detected the Ine protein in the foregut (esophagus), midgut (various regions) and anal plate of Drosophila melanogaster larvae (Fig. 4F-I), as previously reported in the embryo using in situ hybridization (Soehnge et al., 1996). The similarity in the tissue distribution of MasIne in Manduca sexta and Ine in Drosophila melanogaster strongly suggests that the two proteins are orthologs.

\section{Functional characterization}

To elucidate its function, MasIne was expressed in Xenopus oocytes using the two potential start codons, base pairs 135 and 459. Both MasIne-135 and MasIne-459 were expressed at high levels in the plasma membrane of Xenopus oocytes (Fig. 5A-C). Immunoprecipitation using specific antibodies showed that MasIne-135 and MasIne-459 were expressed in Xenopus oocytes injected with the corresponding cRNA (Fig. 5D). The expected molecular mass of MasIne-135 is $81 \mathrm{kDa}$ and that for MasIne-459 is $69 \mathrm{kDa}$. After a $30 \mathrm{~h}$ incubation in medium containing $\left[{ }^{35} \mathrm{~S}\right]$ methionine (pulse), a major band at $80-90 \mathrm{kDa}$ was observed in MasIne-135expressing oocytes, whereas MasIne-459 appeared as a major band at 58-66 kDa. Following an additional $42 \mathrm{~h}$ expression in cold medium (chase), MasIne-135-expressing oocytes had major broad bands at 100-150 and >205 kDa, while MasIne459-expressing oocytes showed bands at 84-116 and $>205 \mathrm{kDa}$, suggesting glycosylation and oligomerization of the proteins.

To monitor whether MasIne could transport a substrate, oocytes expressing the protein were used in uptake assays, as previously described by Mbungu et al. (1995). No uptake was observed with either construct using radiolabeled dopamine, serotonin, norepinephrine, octopamine, histamine, tyramine, glycine, GABA, glutamate, proline, lysine, phenylalanine, leucine, choline, taurine or creatine (data not shown).

To determine whether the expressed MasIne was functional, we tested for ligand-independent leakage currents. MasIne135-expressing oocytes displayed a higher level of $\mathrm{Na}^{+}, \mathrm{Li}^{+}$ and $\mathrm{K}^{+}$leakage current than did MasIne-459-expressing or water-injected oocytes (Fig. 6; Table 1). In addition, MasIne135-expressing oocytes showed significantly higher background currents in Tris- $\mathrm{Cl}$ isotonic solution than did control oocytes (Table 1). The positive controls, rGAT1 and rSERT, also showed ligand-independent leakage currents to $\mathrm{Na}^{+}$and $\mathrm{Li}^{+}$but not to $\mathrm{K}^{+}$(Mager et al., 1994, 1996; data not shown). $\mathrm{K}^{+}$leakage currents have also been observed with Manduca KAAT1 and human DAT (Bossi et al., 1999; 
Hyperosmotic induction of a transporter 3535

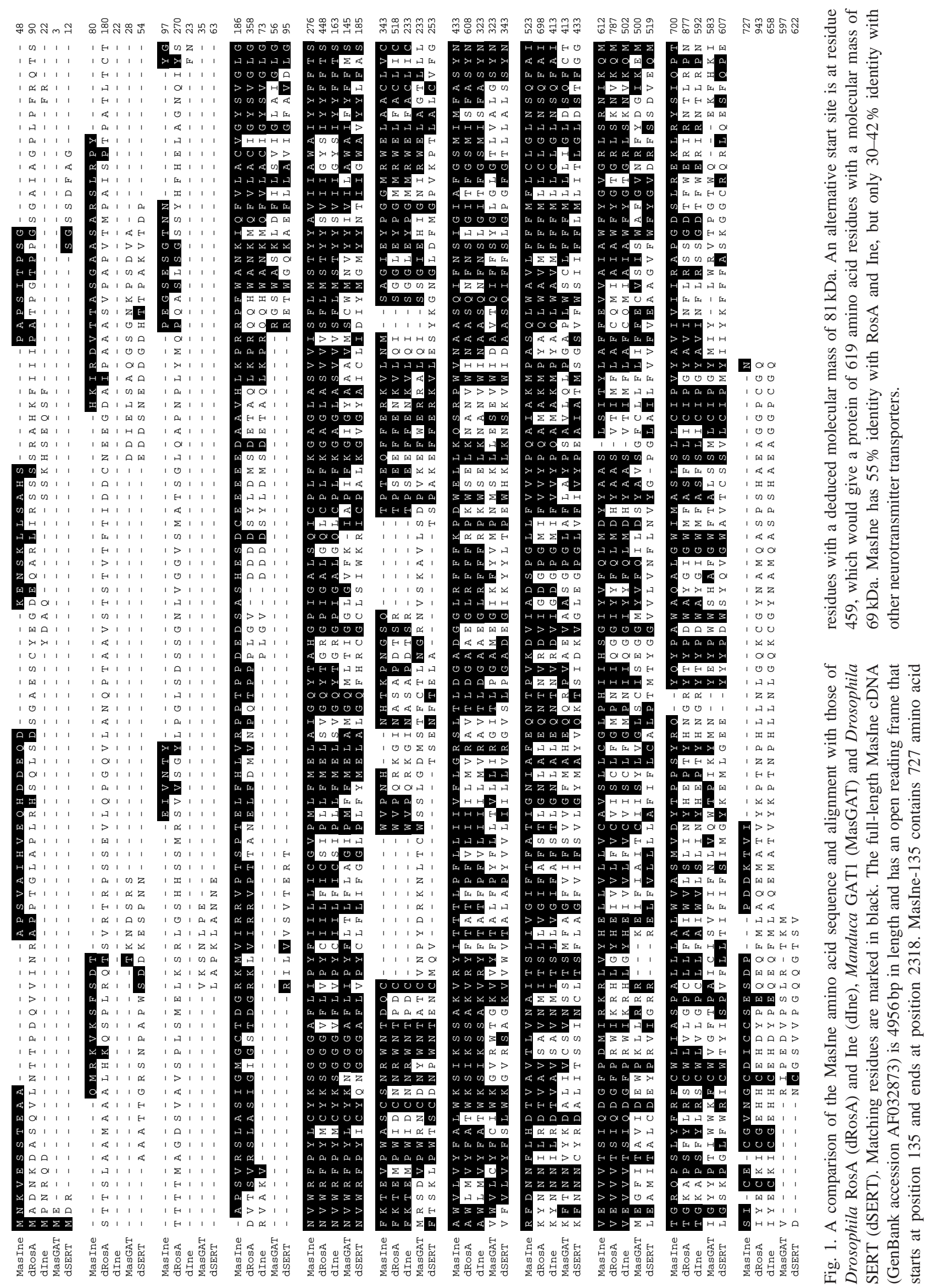




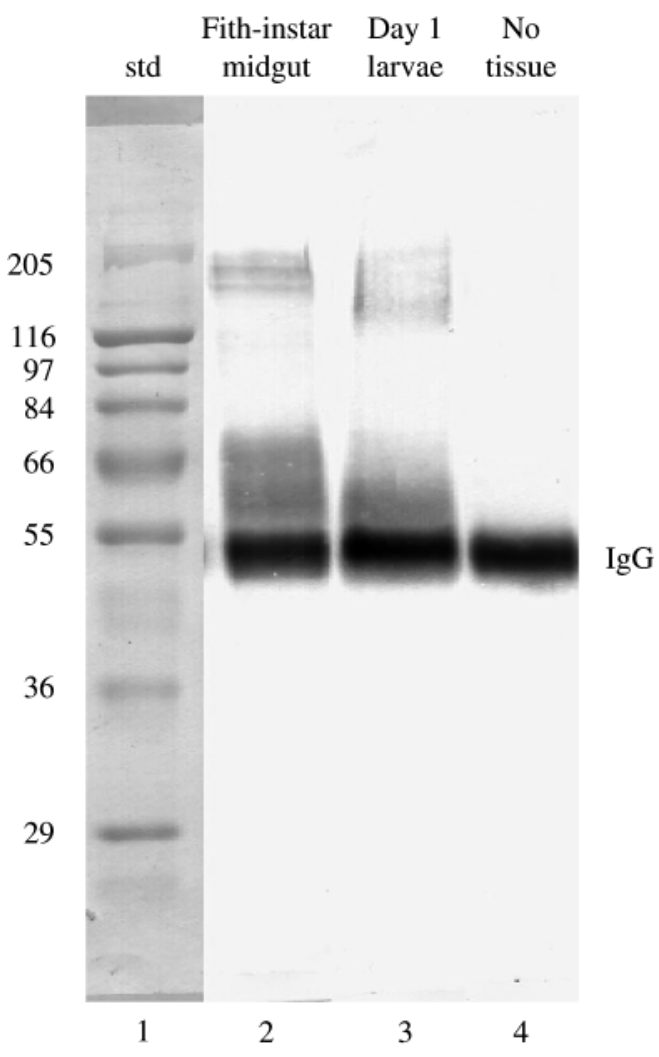

Fig. 2. Immunoprecipitation and western blot of MasIne from different tissues of Manduca sexta larvae. Lane 1 shows the molecular mass standards (std); values are in $\mathrm{kDa}$. Lane 2 shows the immunoprecipitation of MasIne from the midgut of fifth-instar day 1 larvae (approximately 1.5 midgut equivalents) with major bands at 58-80 and 150-205 kDa. Lane 3 shows immunoprecipitates obtained from whole day 1 larvae (approximately 0.14 gequivalent) with broad bands at $58-80$ and $120-205 \mathrm{kDa}$. Lane 4 represents the negative control that contains no tissue. The $55 \mathrm{kDa}$ band observed in all lanes comes from the rabbit MasIne-specific IgG used in immunoprecipitation. Lane 1 was stained with Coomassie Blue, while lanes 2-4 were detected using BCIP/NBT. Preimmune antibody does not immunoprecipitate any of the MasIne bands (data not shown).

Sonders et al., 1997). Thus, MasIne-135 generates a transporter-like leakage current.

MasIne-135-expressing oocytes did not show substrate- independent $\mathrm{Na}^{+}$-coupled transient currents (Fig. 6D), however, nor did MasIne-459-expressing oocytes, although these were observed with rGAT1 (Fig. 6E), rSERT (data not shown) and KAAT1 (Bossi et al., 1999; Mager et al., 1993, 1994). This lack of a transient current suggests either that MasIne-135 does not bind $\mathrm{Na}^{+}$or that the bound $\mathrm{Na}^{+}$does not move within the electric field during voltage steps. These data show that MasIne-135 was functionally expressed in Xenopus oocytes and that it has unique conducting properties compared with other neurotransmitter transporters.

\section{Sensitivity to hyperosmotic stimulation}

During two-electrode voltage-clamp assays, we observed that MasIne-135-expressing oocytes were sensitive to hyperosmotic stimulation $\left(400\right.$ mosmol $\left.\mathrm{l}^{-1}\right)$, displaying $\mathrm{Ca}^{2+}-$ activated $\mathrm{Cl}^{-}$currents $\left(\mathrm{I}_{\mathrm{Cl}(\mathrm{Ca})}\right)$ with kinetics similar to those observed in InsP3-injected oocytes (Hartzell, 1996; Kuruma and Hartzell, 1999). These oocytes responded to hyperosmotic stimulation within $6-15 \mathrm{~s}$ with outwardly rectifying $\mathrm{Cl}^{-}$ currents, which peaked at 40-60 s (Fig. 7A,B), suggesting that $\mathrm{I}_{\mathrm{Cl}-1}$ was induced. With a longer hyperosmotic exposure, the strong outwardly rectifying current decreased, and a significant inward steady current appeared $\left(\mathrm{I}_{\mathrm{Cl}-2}\right)$, reaching its peak in 3-5 min (Fig. 7C). The time course of MasIne-135-mediated current (Fig. 7F) is similar to that observed in $\mathrm{InsP}_{3}$-injected oocytes (Hartzell, 1996; Kuruma and Hartzell, 1999). MasIne459-expressing oocytes and water-injected oocytes showed a small and gradual response to the $400 \mathrm{mosmoll}^{-1}$ stimulation (Fig. 7F). When water-injected oocytes were stimulated by 725 mosmol $\mathrm{l}^{-1}$ (isotonic solution plus $500 \mathrm{mmoll}^{-1}$ sucrose), we were able to measure a BAPTA-sensitive $\mathrm{Cl}^{-}$current that started to increase after more than $80 \mathrm{~s}$ (data not shown). However, some batches of oocytes, when stimulated at $725 \mathrm{mosmol}^{-1}$, and using the same voltage-step protocol, developed steady inward and outward $\mathrm{Cl}^{-}$currents controlled by unknown mechanisms. Our data represent only those batches of oocytes that did not show such currents.

The rapid response to $400 \mathrm{mosmoll}^{-1}$ solutions was not observed in MasIne-459- (Fig. 7D,E), rGAT1- or rSERTexpressing oocytes (Fig. 7G) indicating that the MasIne-135induced $\mathrm{Cl}^{-}$currents were specific. Tail current measurements (data not shown) and the current/voltage (I/V) relationship (Fig. 7G) gave a reversal potential for the osmotically induced

Table 1. Leakage current measurement on MasIne-expressing oocytes

\begin{tabular}{lccc}
\hline & \multicolumn{3}{c}{ Current (nA) } \\
\cline { 2 - 4 } & Tris-Cl & $\mathrm{NaCl}$ & $\mathrm{KCl}$ \\
\hline MasIne-135 & $-59.4 \pm 7.2(19)$ & $-201.0 \pm 22.2(13)$ & $-284.2 \pm 38.5(8)$ \\
MasIne-459 & $-34.2 \pm 5.6(8)$ & $-83.7 \pm 20.5(5)$ & $\mathrm{ND}$ \\
$\mathrm{H}_{2} \mathrm{O}$ - or non-injected & $-27.0 \pm 6.7(18)$ & $-103.0 \pm 28.7(8)$ & $-166.8 \pm 32.1(5)$
\end{tabular}

All leakage currents, in $\mathrm{nA}$, were taken from data in the $\mathrm{I}_{\mathrm{Cl}-1}$ voltage step protocol (see Materials and methods) at the $-80 \mathrm{mV}$ step. The currents are averages of the recording between 160 and $190 \mathrm{~ms}$ after the step.

Tris-Cl represents the Tris-Cl-based isotonic solution, while $\mathrm{NaCl}$ and $\mathrm{KCl}$ represent the corresponding substituted isotonic solutions.

Values are means \pm S.E.M. $(N)$. 

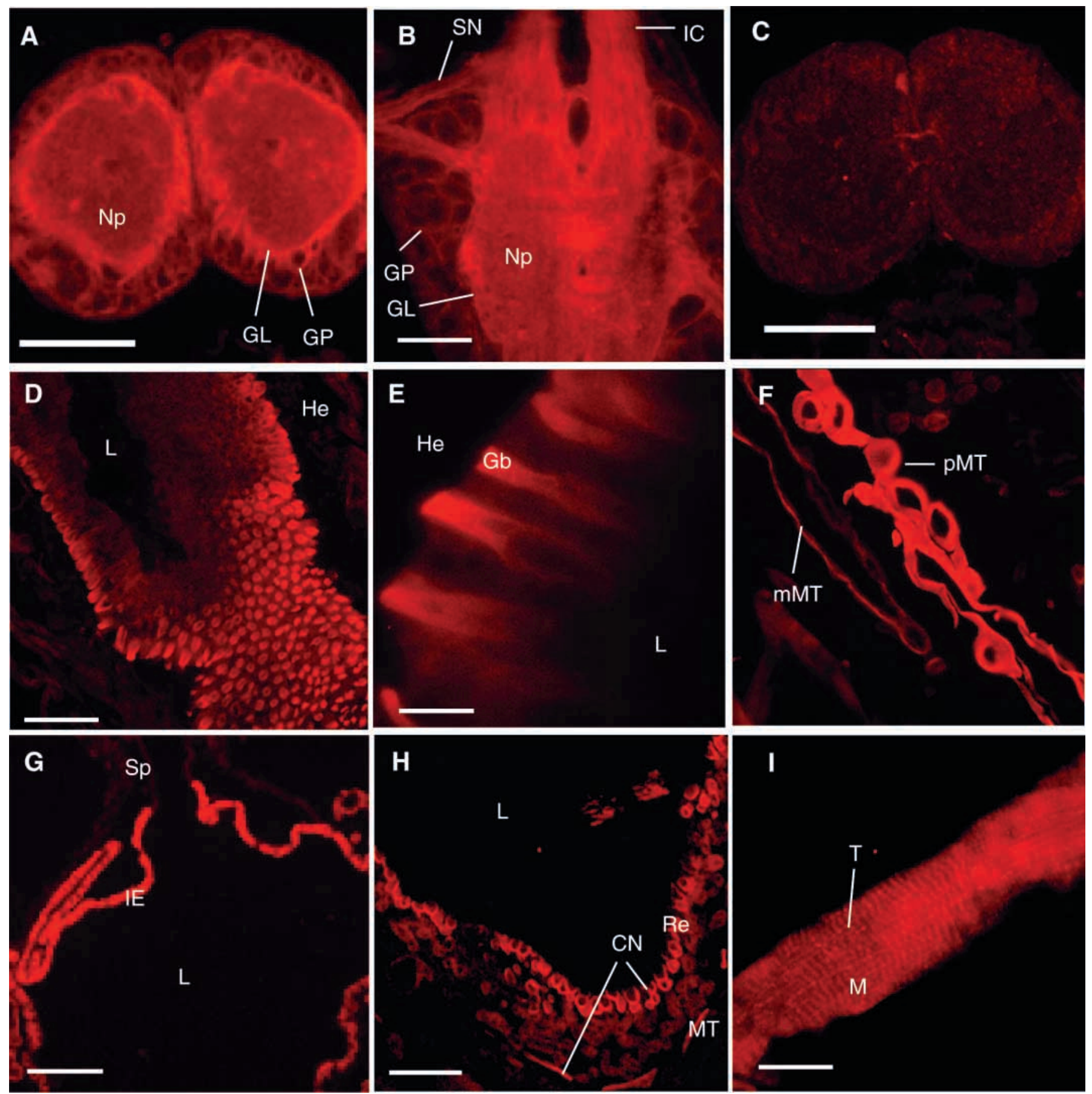

Fig. 3. Tissue distribution of MasIne in Manduca sexta. (A) In the third-instar larval brain, MasIne was highly and uniformly expressed throughout the neuropil (Np) and the glial cell layer (GL) and its processes (GP). (B) MasIne expression in the first abdominal ganglion of a third-instar Manduca sexta larva. High levels of expression were observed in the glial cell layer (GL) and its processes (GP), the axons in the neuropil (Np), the intersegmental connectives (IC) and the segmental nerve (SN). (C) The preimmune serum did not interact with the thirdinstar larval brain. (D,E) MasIne expression is restricted to the basolateral membrane of midgut goblet cells $(\mathrm{Gb})$; He, hemolymph side of the midgut; L, lumen side of the midgut. (F) High levels of MasIne expression were observed in the proximal region (pMT), but very low levels of expression were observed in the middle region (mMT) of the Malpighian tubule. (G) Iliac epithelial cells (Ie) showed high MasIne levels, but MasIne was not expressed in the sphincter (Sp) region. (H) MasIne was expressed in the basolateral membrane of epithelial cells of the rectum $(\mathrm{Re})$ and the outer flat Malpighian tubules (MT), but very low levels of expression were observed in the round inner Malpighian tubules in the cryptonephridial system (CN). (I) In the leg muscle (M) of third-instar Manduca sexta, MasIne was expressed on T-tubules (T). Scale bars: A,B,C,F,H, $100 \mu \mathrm{m} ; \mathrm{E}, \mathrm{I}, 20 \mu \mathrm{m} ; \mathrm{G}, 200 \mu \mathrm{m}$. 

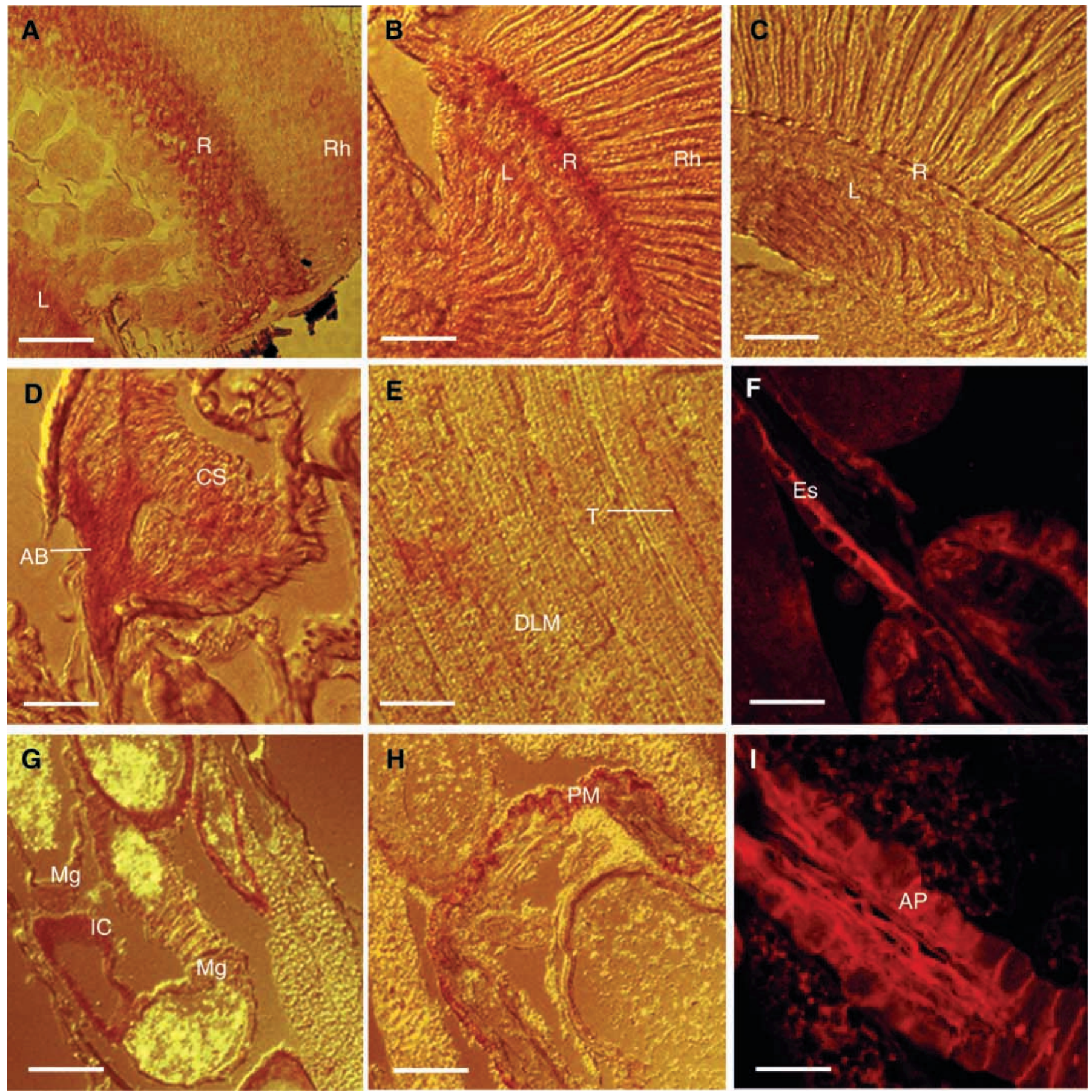

Fig. 4. Tissue distribution of MasIne in Manduca sexta and Ine in Drosophila melanogaster. (A) MasIne was expressed in the retinula (R), in both the rhabdomere $(\mathrm{Rh})$ and the cell bodies, in the axons of the optic nerves, in the lamina (L) and in the axon projections to the medulla in the visual system. (B) In the visual system, Ine (or RosA) expression was observed in the retinula cells (R) in both the cell body and rhabdomere $(\mathrm{Rh})$, the lamina cortex $(\mathrm{L})$ and the axonal projection to the medulla. (C) Sections treated with preimmune serum showed no immunoreactivity to Ine in the visual system. (D) In the antennal Johnston's organ, Ine was expressed in the chordotonal sensilla (CS) and the axon bundle $(\mathrm{AB})$ projection to the brain. (E) The dorsal longitudinal indirect flight muscle (DLM) shows Ine expression in the T-tubule system (T). (F) Ine was expressed in the apical and lateral membrane of the esophagus (Es). (G,H) Ine was expressed in the midgut (Mg) iron cell (IC) region and in the posterior midgut (PM) region. (I) Ine was expressed in the plasma membrane of the larval anal plate epithelial cells (AP). Scale bars: A,B,C,F,G,H, $50 \mu \mathrm{m}$; D,E,I, $20 \mu \mathrm{m}$.

current at $-19 \mathrm{mV}$, which is close to the $\mathrm{Cl}^{-}$equilibrium potential $\left(E_{\mathrm{Cl}}\right)$. In addition, substitution of extracellular $\mathrm{Cl}^{-}$ with gluconate abolished this induced outward current, suggesting activation of a $\mathrm{Cl}^{-}$conductance (Fig. $\left.7 \mathrm{H}\right)$. When 

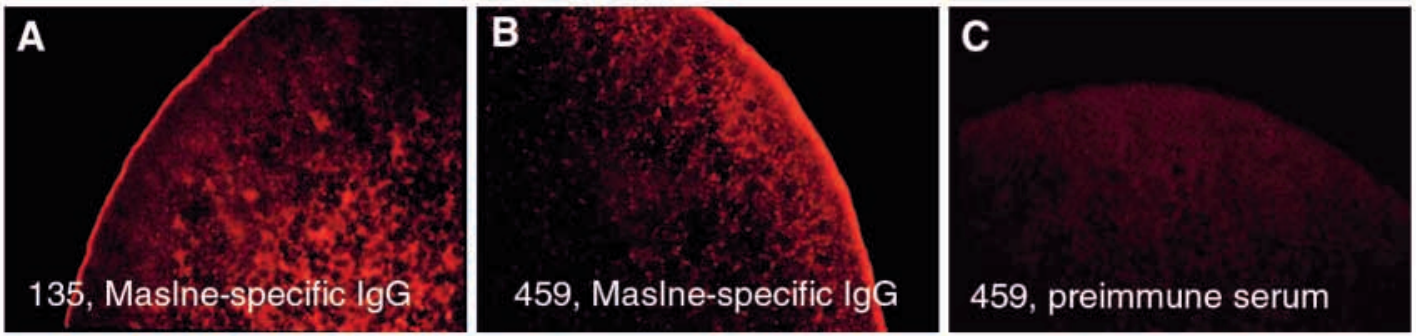

\section{D}

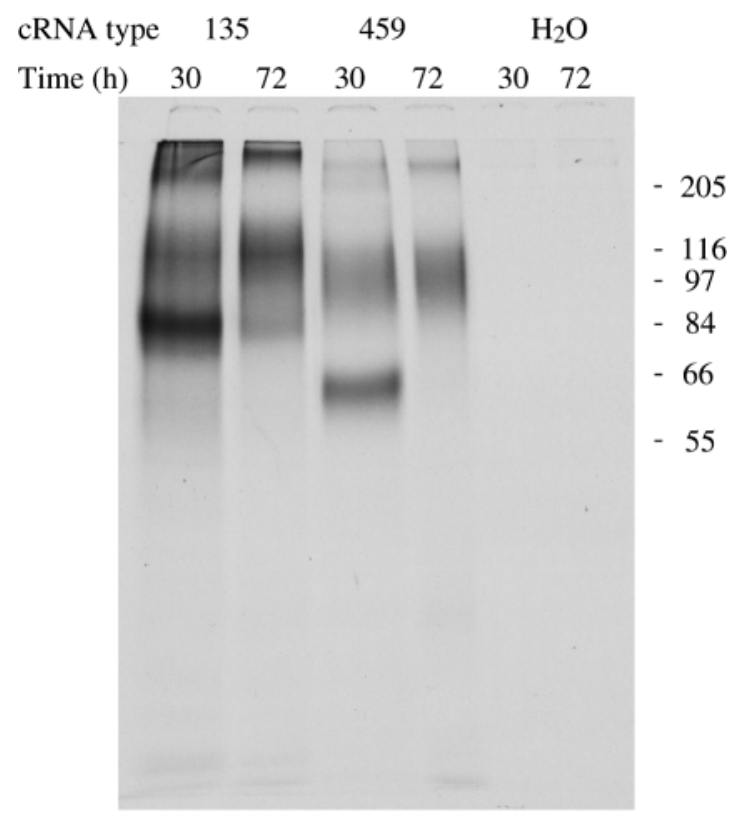

Fig. 5. Immunohistochemistry and immunoprecipitation of MasIne in Xenopus oocytes. (A,B) MasIne-135 (A) and MasIne-459 (B) are expressed in the oocyte plasma membrane. The red intracellular staining indicates newly synthesized MasIne. (C) The same oocyte as in B, but incubated with preimmune serum, showing the specificity of the purified anti-MasIne IgG. Preimmune serum also showed no interaction with MasIne-135-expressing oocytes. In addition, waterinjected oocytes showed no cross reactivity with MasIne-specific IgG (data not shown). (D) Immunoprecipitation of MasIne expressed in Xenopus oocytes (equivalent to approximately eight oocytes). In the $30 \mathrm{~h}$ pulse, a major band with a molecular mass of approximately $80-90 \mathrm{kDa}$, which is the size of the putative unglycosylated monomer, was detected in oocytes expressing MasIne-135. Following a $42 \mathrm{~h}$ chase, two major bands were observed at 100-150 kDa and >205 kDa, which probably represent the glycosylated and the oligomer bands. From oocytes expressing MasIne-459, major bands at 58-66 kDa and at $84-116 \mathrm{kDa}$ were obtained after the $30 \mathrm{~h}$ pulse. Following a $42 \mathrm{~h}$ chase, the major bands were found at are 84-116 and >205 kDa, also representing the glycosylated and the oligomer bands. No detectable bands were observed in immunoprecipates obtained from oocytes injected with water.

Tris ${ }^{+}$was replaced with $\mathrm{Na}^{+}$or $\mathrm{K}^{+}$, there was no change in the reversal potential (Fig. $7 \mathrm{H}$ ). To characterize the osmotically induced currents, we chose to use Tris- $\mathrm{Cl}$ for subsequent experiments.
Table 2. Effect of pharmacological agents on $\mathrm{Ca}^{2+}$-activated $\mathrm{Cl}^{-}$currents in MasIne-135-expressing oocytes

\begin{tabular}{|c|c|}
\hline Treatment & Percentage activity ${ }^{1}$ \\
\hline Untreated $(N=15)$ & $100 \pm 5.1$ \\
\hline Niflumic acid, $1 \mathrm{mmol}^{-1}(N=5)$ & $17.3 \pm 8.6$ \\
\hline NPPB, $100 \mu \mathrm{moll}^{-1}(N=5)$ & $41.2 \pm 9.5$ \\
\hline Lanthanum chloride, $4 \mathrm{mmoll}^{-1}(N=5)$ & $294.3 \pm 5.1$ \\
\hline BAPTA-AM, $50 \mu \mathrm{moll}^{-1}(N=8)^{2}$ & $8.7 \pm 1.4$ \\
\hline EGTA, $0.6 \mathrm{nmol}$ injected $(N=4)^{3}$ & $9.2 \pm 3.8$ \\
\hline EGTA, $5 \mathrm{mmoll}^{-1}(N=6)$ & $102.2 \pm 4.5$ \\
\hline Heparin, $0.6 \mu \mathrm{g}$ injected $(N=6)$ & $4.9 \pm 8.7$ \\
\hline $\mathrm{U} 73122,2 \mu \mathrm{moll}^{-1}(N=6)^{4}$ & $32.0 \pm 8.1$ \\
\hline $\mathrm{U} 73343,2 \mu \mathrm{moll}^{-1}(N=6)^{4}$ & $110.3 \pm 10.4$ \\
\hline GDP- $\beta-\mathrm{S}, 0.2 \mathrm{nmol}$ injected $(N=5)^{3}$ & $119.3 \pm 28$ \\
\hline $\begin{array}{l}\text { MasIne-459-expressing oocytes, } \\
\text { untreated }(N=19)\end{array}$ & $11.7 \pm 8.4$ \\
\hline $\begin{array}{l}\text { Water-injected oocytes, untreated } \\
\qquad(N=12)\end{array}$ & $5.2 \pm 8.0$ \\
\hline
\end{tabular}

${ }^{1}$ Percentage activity was normalized to currents observed in untreated MasIne-135-expressing oocytes exposed to $400 \mathrm{mosmol}^{-1}$ hyperosmotic stimulation, and the maximum outward current during a voltage step from -40 to $+100 \mathrm{mV}$ was measured. Oocytes were exposed to the agent in the superfusion solution unless indicated otherwise.

${ }^{2}$ Incubated for $5 \mathrm{~h}$ before recording.

${ }^{3}$ Incubated for $15 \mathrm{~min}$ after injection before recording.

${ }^{4}$ Incubated for $15 \mathrm{~min}$ prior to superfusion.

Values are means \pm S.E.M. with the control value taken as $100 \%$.

\section{Pharmacological characterization of MasIne-135-induced currents}

Niflumic acid and NPPB blocked the osmotically induced conductance (Table 2), while, $\mathrm{La}^{3+}$, a stimulator of $\mathrm{Ca}^{2+}$ activated $\mathrm{Cl}^{-}$channels (Ackerman et al., 1994), potentiated it (Table 2). Incubation with BAPTA-AM also completely blocked this current (Table 2), as did injection of EGTA (Table 2). Extracellular $\mathrm{Ca}^{2+}$ did not affect it, since the addition of $5 \mathrm{mmoll}^{-1}$ EGTA to the $\mathrm{Ca}^{2+}$-free superfusion solution did not affect the amplitude of the response (Table 2). Thus, hyperosmotic stimulation of MasIne-135 apparently causes intracellular $\mathrm{Ca}^{2+}$ release, thereby activating $\mathrm{I}_{\mathrm{Cl}(\mathrm{Ca})}$ in Xenopus oocytes (Ackerman et al., 1994; Hartzell, 1996; Kuruma and Hartzell, 1999).

Since the kinetics of the currents observed here are similar to those observed in $\mathrm{InsP}_{3}$-injected oocytes, we proposed that the $\mathrm{InsP}_{3}$ signaling cascade is involved in the MasIne-135- 
A

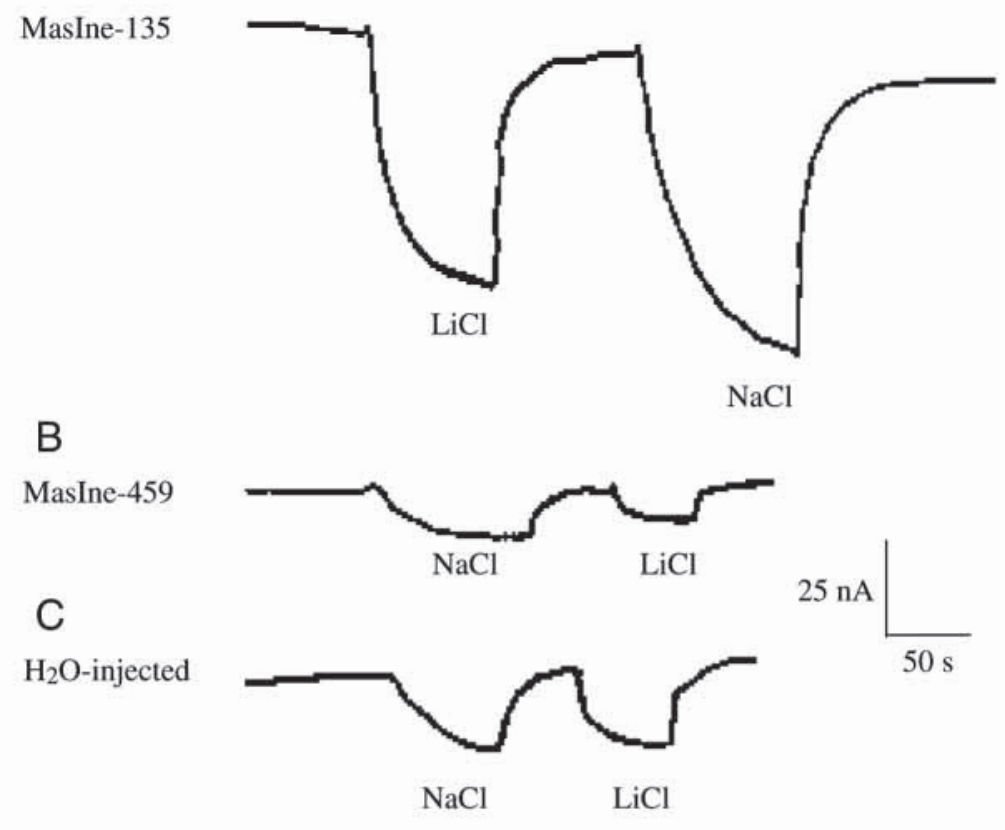

Fig. 6. MasIne-135-expressing oocytes showed higher $\mathrm{Na}^{+}$and $\mathrm{Li}^{+}$leakage currents than MasIne-459expressing or water-injected oocytes. The oocyte membrane potential was at $-60 \mathrm{mV}$, and the oocytes were superfused with Tris- $\mathrm{Cl}$ isotonic solution followed by either ND96 or a $\mathrm{Li}^{+}$-substituted ND96. (A) MasIne-135-expressing oocytes show a single leakage current for ND96 and for $\mathrm{Li}^{+}$substitution (average peak currents were $-106 \pm 9 \mathrm{nA}, N=6$, for ND96 and $-70 \pm 3 n A, N=3$, for $\mathrm{Li}^{+}$-substituted ND96; means \pm S.E.M.). When oocytes were superfused with Tris- $\mathrm{Cl}$ isotonic solution, there was also a steadily increasing leakage current $\left(-2.1 \pm 0.2 \mathrm{nA} \mathrm{min}^{-1} ; N=6\right)$. (B) MasIne-459-expressing oocytes showed smaller leakage currents for ND96 and for $\mathrm{Li}^{+}$substitution $(-10.8 \pm 1.0 \mathrm{nA}, N=4$, for ND96 and $-7.8 \pm 0.5 \mathrm{nA}, N=4$, for $\mathrm{Li}^{+}$-substituted ND96). (C) Water-injected oocytes showed small leakage currents for ND96 and for $\mathrm{Li}^{+}$ substitution (averages were $-17.8 \pm 1.7 \mathrm{nA} ; N=4$, for ND96 and $-18.7 \pm 0.9 \mathrm{nA}, N=3$, for $\mathrm{Li}^{+}$-substituted ND96). (D) MasIne-135 did not induce $\mathrm{Na}^{+}$-dependent transient currents, but these were induced by rGAT1 (E). These traces were obtained by subtracting voltage step traces between ND96 and Tris-Cl isotonic perfusions.

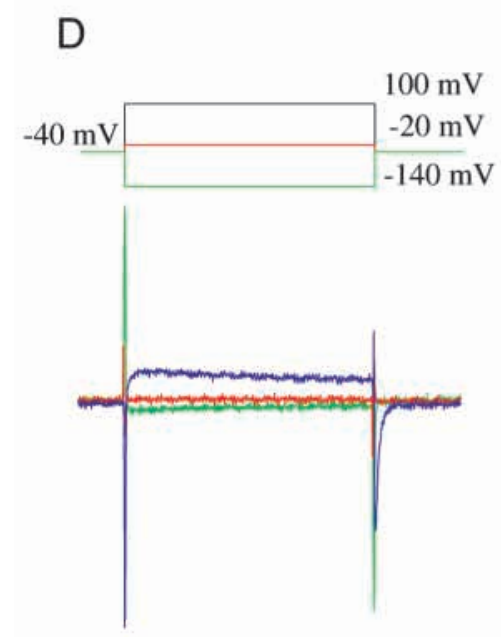

mediated current. To test this hypothesis, oocytes were injected with heparin, an $\mathrm{InsP}_{3}$ receptor inhibitor, or were incubated with U73122, a permeable phospholipase C (PLC) inhibitor. These compounds inhibited the osmotic MasIne response (Table 2). However, the inactive analogue of U73122, U73343, did not affect the response, showing that the action of U73122 is specific. Injection of GDP- $\beta-S$, a G-protein inhibitor, had no effect on the MasIne-135-mediated current (Table 2). Thus, activated MasIne-135 stimulates the $\mathrm{PLC} / \mathrm{InsP}_{3}$ signaling cascade but not through a G-protein pathway.

\section{Function of the MasIne-135 N terminus}

Since oocytes expressing MasIne-135 responded to hyperosmotic stimuli, resulting in intracellular $\mathrm{Ca}^{2+}$ release, but oocytes expressing MasIne-459 did not, we hypothesized that the N-terminal 108 amino acid residues played a crucial role. To test this hypothesis, we fused the N-terminal 108 amino acid residues of MasIne-135 with rGAT1 which, on its own, did not respond to hyperosmotic stimuli. Oocytes expressing this fusion construct, 108-rGAT1, spontaneously gave rise to a combination of both outwardly rectifying $\mathrm{Cl}^{-}$ and inward steady leakage currents even without hyperosmotic stimulation (Fig. 8A). Both currents were also observed in MasIne-135-expressing oocytes after hyperosmotic stimuli of more than $3 \mathrm{~min}$ (Fig. 7C). In addition, both the outward and inward currents were inhibited by BAPTA-AM; however, BAPTA-insensitive steady $\mathrm{Cl}^{-}$ currents were also observed (Fig. 8B). These data suggest that 108-rGAT1 mediated three currents, $\mathrm{I}_{\mathrm{Cl}-1}$ and $\mathrm{I}_{\mathrm{Cl}-2}$, both sensitive to BAPTA, and a BAPTA-insensitive leakage $\mathrm{Cl}^{-}$ current (Hartzell, 1996) (Fig. 8C). Our interpretation of these data is that 108-rGAT1 activated a constant release of intracellular $\mathrm{Ca}^{2+}$ and, as a consequence, $\mathrm{ICl}_{\mathrm{Cl}} 1, \mathrm{I}_{\mathrm{Cl}-2}$ and leakage currents were activated. The currents observed with 
Fig. 7. MasIne-135- and MasIne-459mediated currents during exposure to isotonic and hyperosmotic stimulation solutions. (A) Traces of MasIne-135mediated currents when the oocyte was superfused with Tris- $\mathrm{Cl}$ isotonic solution. (B,C) The same oocyte gave outwardly rectifying $\mathrm{Cl}^{-}$currents within $40 \mathrm{~s}$ (B) and $3 \mathrm{~min}$ (C) of exposure to hyperosmotic stimulation $\left(400\right.$ mosmol l$\left.^{-1}\right)$. (D) Traces from MasIne-459-expressing oocytes in response to isotonic solution. (E) The response of the same oocyte to a $40 \mathrm{~s}$ hyperosmotic stimulation. (F) The time course of the response of MasIne-135and MasIne-459-expressing and waterinjected oocytes to $400 \mathrm{mosmoll}^{-1}$ stimulation measured by its maximum outward (at $+100 \mathrm{mV}$ step) and inward (at $-140 \mathrm{mV}$ step) currents. Time zero (indicated by an arrow) represents the time that the oocyte was exposed to the hyperosmotic solution. MasIne-135expressing oocytes responded to 400 mosmol $^{-1}$ stimulation and mediated outward current (open circles) within $20 \mathrm{~s}$ of exposure to the hyperosmotic solution; the current peaked at $40 \mathrm{~s}$. The peak current dropped quickly (within 60s) to a relatively steady current approximately $1 \mu \mathrm{A}$ above the background current. The MasIne-135-mediated inward current (filled circles) did not increase significantly until the outward current had dropped to a steady level (at $120 \mathrm{~s}$ ). The MasIne-459-expressing and waterinjected oocytes showed a small increase in outward currents (open squares, MasIne-459 outward current; open triangles, water-injected outward current) in response to the 400 mosmol $^{-1}$ stimulation. The inward currents (filled squares, MasIne-459 inward current; filled triangles, waterinjected inward current) did not show any significant change over the $7 \mathrm{~min}$ of exposure to hyperosmotic solution. (G) Current/voltage (I/V) plot of hyperosmotic-stimulated currents. MasIne-135-expressing oocytes exposed to hyperosmotic solution for $40 \mathrm{~s}$ (open circles, $N=15$ ) and 3 min (filled red diamonds, $N=5$ ). MasIne-459- (filled red circles, $N=19$ ), rGAT1- (open upward triangles, $N=6$ ) and rSERT-expressing oocytes (filled downward triangles, $N=5$ ) and uninjected oocytes (open diamonds, $N=12$ ), all recorded after a $40 \mathrm{~s}$ exposure to hyperosmotic solution. Hyperosmotic-stimulated currents were obtained by subtracting the currents between hyperosmotic and isotonic solution exposures. (H) The effects of ion substitution on the MasIne-mediated current. Currents obtained using Tris-Cl superfusion are shown by black open circles $(N=15)$. Substitution of $\mathrm{Cl}^{-}$with gluconate shifted the reversal potential to more positive potentials and reduced its magnitude (green downward triangle; $N=3$ ). $\mathrm{K}^{+}$(red filled upward triangle; $N=9$ ) and $\mathrm{Na}^{+}$(blue filled diamond; $N=6$ ) substitution for Tris ${ }^{+}$did not change the reversal potential, but $\mathrm{K}^{+}$slightly reduced and $\mathrm{Na}^{+}$significantly increased the magnitude of the current. Values are means \pm S.E.M.

108-rGAT1 were not seen in oocytes expressing wild-type rGAT1 (Fig. 8C), suggesting that the MasIne $\mathrm{N}$ terminus was modulating these effects.

GABA transport by 108-rGAT1 was approximately $10 \%$ of that of rGAT1 but approximately 10 times that of uninjected oocytes $\left(92 \pm 9 \mathrm{fmoloocyte}^{-1} 30 \mathrm{~min}^{-1}\right.$ for 108 rGAT1, $870 \pm 58 \mathrm{fmol}_{\text {oocyte }}{ }^{-1} 30 \mathrm{~min}^{-1}$ for rGAT1 and $9 \pm 2 \mathrm{fmol} \mathrm{oocyte}^{-1} 30 \mathrm{~min}^{-1}$ for uninjected oocytes; means \pm 


\section{C.-S. CHIU AND OTHERS}

Fig. 8. The time course and pharmacology of currents in oocytes expressing 108-rGAT1. (A) Oocytes superfused with Tris-Cl isotonic solution displayed spontaneous inward and outward $\mathrm{Cl}^{-}$currents. (B) These $\mathrm{Cl}^{-}$currents were inhibited by BAPTA-AM $\quad\left(200 \mu \mathrm{moll}^{-1}, \quad 1-2 \mathrm{~h}\right.$ incubation). (C) Current/voltage $(I / V)$ plot of 108-rGAT1-expressing oocytes before (open circles; $N=9$ ) and after (filled squares; $N=9$ ) BAPTA-AM treatment. Oocytes expressing rGAT1 on its own gave only background currents in response to Tris- $\mathrm{Cl}$ isotonic solution (filled upward triangle, $N=9$ ). Values are means \pm S.E.M.

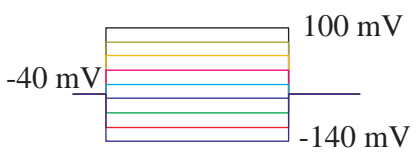

A

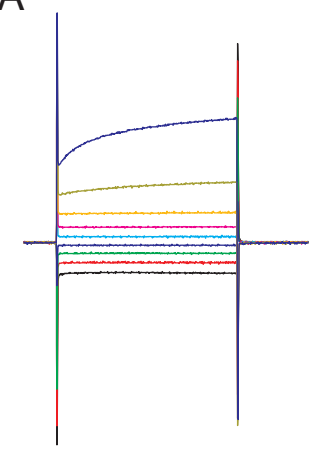

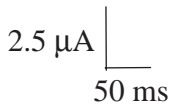

B

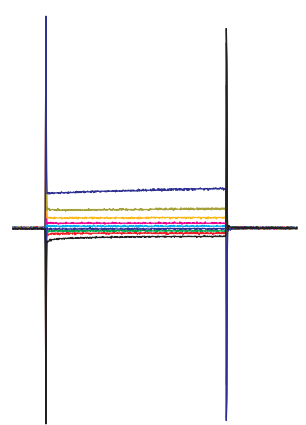

C

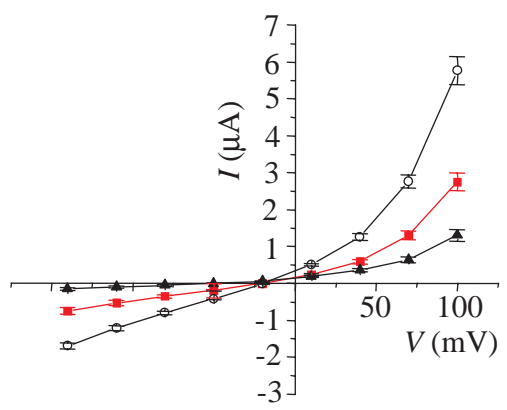

S.E.M., $N=5$ ). The lower GABA uptake by 108 -rGAT1 may be caused by the less negative membrane potential in these oocytes, which would reduce the driving force for ligand uptake.
Since the $\mathrm{N}$ terminus activated spontaneous $\mathrm{Ca}^{2+}$-activated currents in 108-rGAT1-expressing oocytes but not in MasIne135-expressing oocytes, we hypothesized that other domains of MasIne-135 interact with the $\mathrm{N}$ terminus, thereby
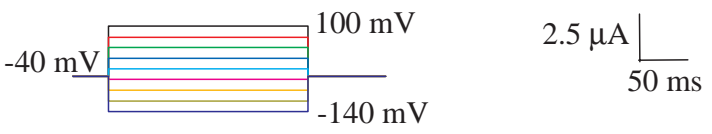

A

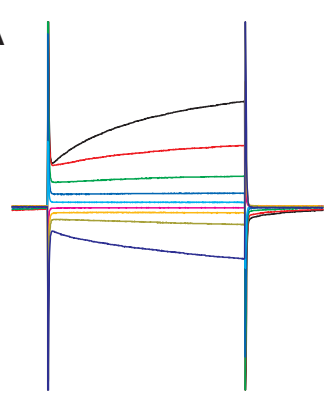

B

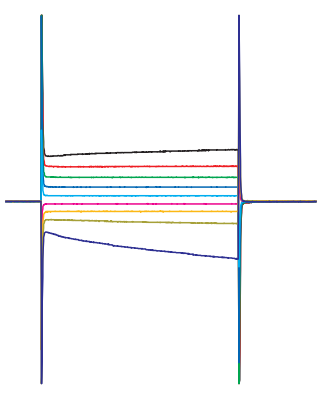

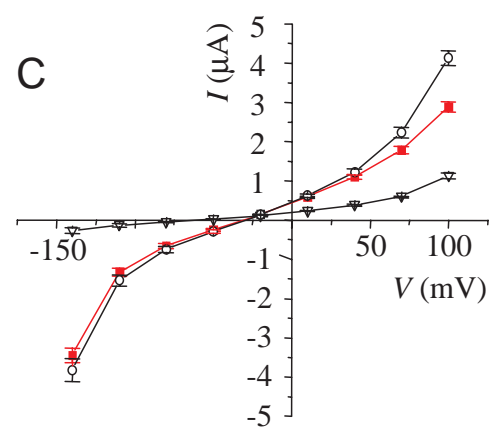

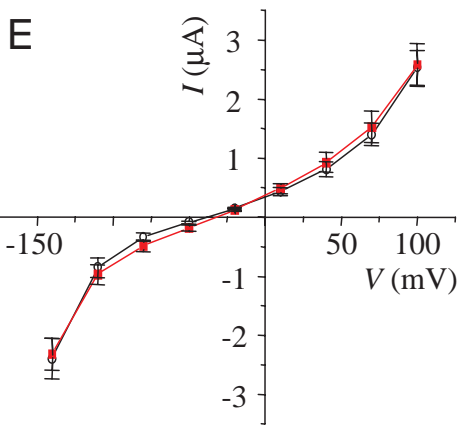

Fig. 9. The time course and pharmacology of oocytes expressing $\Delta$ MasIne using the 'I $\mathrm{Il}_{\mathrm{Cl}-1}$ voltage-step' protocol. (A) $\Delta \mathrm{MasIne-135-expressing}$ oocytes, superfused with Tris-Cl isotonic solution, displayed spontaneous inward and outward $\mathrm{Cl}^{-}$currents, which were inhibited by K4BAPTA (2.5 nmol per oocyte, $15 \mathrm{~min}$ after injection) (B). (C) Current/voltage ( $I / V)$ plot of $\Delta$ MasIne-13-expressing oocytes 5 (open circles; $N=12$ ), $\Delta$ MasIne-135-expressing oocytes treated with $\mathrm{K}_{4} \mathrm{BAPTA}$ (filled circles; $N=12$ ) and $\Delta$ MasIne-459-expressing oocytes (open downward triangles; $N=9$ ). (D) $I / V$ plot of the $\Delta$ MasIne-135-mediated current (open squares; $N=6)$ and its inhibition by $\mathrm{U}_{73122}\left(2 \mu \mathrm{mol} 1^{-1} ; 40 \mathrm{~min}\right.$ incubation; filled downward triangle; $N=6$ ). (E) $I / V$ plot of the $\Delta$ MasIne-135-mediated current before (open circles; $N=6$ ) and after U73343 treatment $\left(2 \mu \mathrm{moll}^{-1} ; 70 \mathrm{~min}\right.$ incubation; red squares, $\left.N=6\right)$. Values are means \pm S.E.M. 


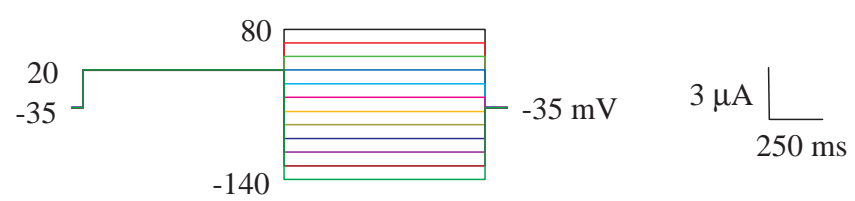

A

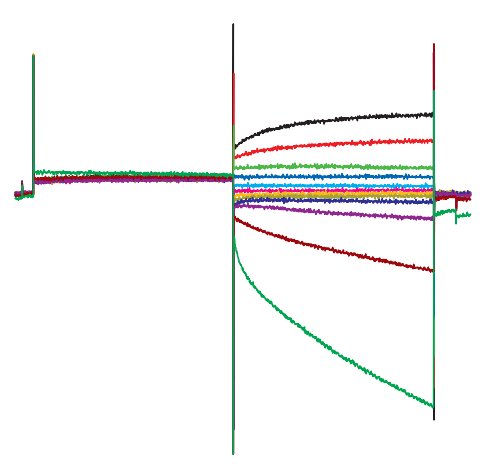

C

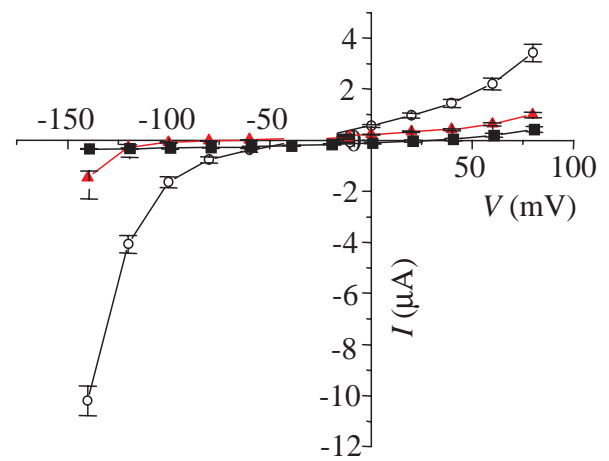

B

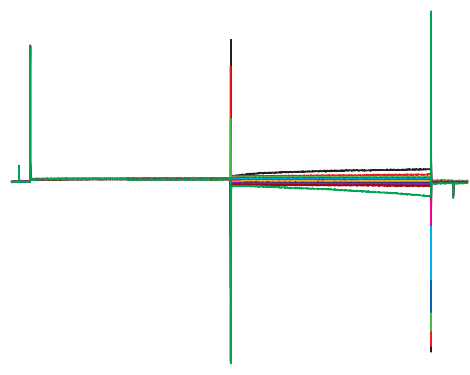

D

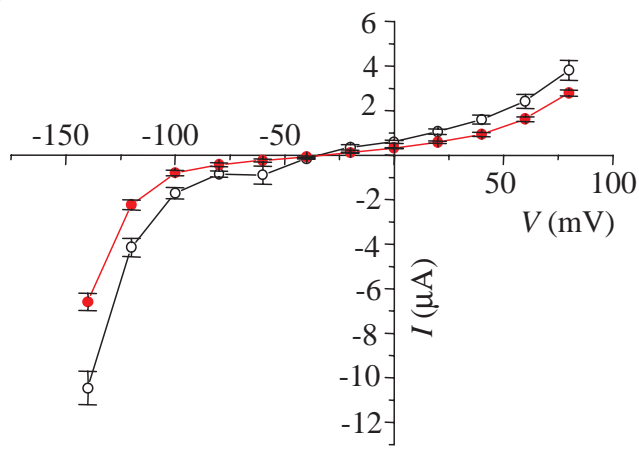

Fig. 10. Time course and pharmacology of $\Delta$ MasIne-mediated currents measured using the 'I $\mathrm{Cl}_{-2}$ voltage-step' protocol. (A) $\Delta \mathrm{Mas} I n e-135$ expressing oocytes, superfused with Tris-Cl isotonic solution, displayed spontaneous inward and outward $\mathrm{Cl}^{-}$currents. (B) $\Delta \mathrm{MasIne}-459$-mediated non-selective cation current in response to hyperpolarizing steps. (C) Current/voltage $(I / V)$ plot of $\Delta$ MasIne-135- and $\Delta$ MasIne-459-mediated currents. $\Delta$ MasIne-135-expressing oocytes (open circles; $N=11)$ mediated $\mathrm{Ca}^{2+}$-activated $\mathrm{Cl}^{-}$currents $\left(\mathrm{I}_{\mathrm{Cl}(\mathrm{Ca})}\right)$ and a hyperpolarized activated $\mathrm{Cl}^{-}$ current $\left(\mathrm{I}_{\mathrm{Cl}(h)}\right)$. $\Delta$ MasIne-459-expressing oocytes ( red triangles; $N=12$ ), superfused with Tris-Cl isotonic solution, mediated an endogenous nonselective cation current, while the non-injected oocytes (filled squares; $N=6$ ) displayed significantly smaller currents. (D) $\Delta \mathrm{Mas} I n e-135$-mediated $\mathrm{Cl}^{-}$currents are sensitive to heparin. The $\Delta$ MasIne-135-expressing oocytes were recorded before heparin injection (open circles; $N=7$ ). The same batch of oocytes was injected with heparin $(460 \mathrm{ng} ; 3.5 \mathrm{~h}$ of incubation) and reassayed (red circles; $N=6$ ). Values are means \pm S.E.M.

regulating MasIne function. To test this hypothesis, MasIne deletion constructs were made to express only the $\mathrm{N}$ terminus. In these constructs, the 10 C-terminal putative transmembrane regions of both MasIne-135 and MasIne-459 were deleted giving $\Delta$ MasIne-135 and $\Delta$ MasIne-459, respectively. When expressed in oocytes, $\Delta$ MasIne-135, but not $\Delta$ MasIne-459, activated the spontaneous outward and inward $\mathrm{Cl}^{-}$currents without hyperosmotic stimulation (Figs 9A,C, 10A-C). Injection of $\mathrm{K}_{4} \mathrm{BAPTA}$ significantly reduced the outward $\mathrm{Cl}^{-}$current, while the strong inwardly rectifying $\mathrm{Cl}^{-}$current was only slightly affected, suggesting that a large proportion of the inward $\mathrm{Cl}^{-}$current was $\mathrm{Ca}^{2+}$ independent (Fig. 9B,C). We believe that this BAPTAinsensitive inward $\mathrm{Cl}^{-}$current differs from $\mathrm{I}_{\mathrm{Cl}-2}$ (Hartzell,
1996), as discussed below. Treatment of these oocytes with U73122, but not U73343, inhibited approximately $45 \%$ of both inward and outward currents (Fig. 9D,E). Heparin treatment also inhibited approximately $40 \%$ of the inward current (Fig. 10D). These results demonstrate that $\Delta$ MasIne135 spontaneously activates the $\mathrm{InsP}_{3}$ signaling cascade and support our hypothesis that other domains of MasIne interact with its $\mathrm{N}$ terminus and regulate its function negatively.

Our results suggest that $\Delta$ MasIne-135, like 108-rGAT1, spontaneously activated $\mathrm{I}_{\mathrm{Cl}-1}$, $\mathrm{I}_{\mathrm{Cl}-2}$ and steady leakage currents through the $\mathrm{InsP}_{3}$ signaling pathway. In addition, $\Delta$ MasIne-135 also mediated an endogenous, hyperpolarization-activated $\mathrm{Cl}^{-}$ current $\left(\mathrm{I}_{\mathrm{Cl}(h)}\right)$ (Figs 9B,C, 10A) (Kowdley et al., 1994; Tokimasa and North, 1996). $\mathrm{I}_{\mathrm{Cl}(h)}$ was probably dependent on 
$\mathrm{InsP}_{3}$ signaling because it was sensitive to heparin (Fig. 10D) and U73122 (Fig. 9D,E). However, as reported by Parker and Miledi (1988), $\mathrm{ICl}(h)$ was not activated by $\mathrm{Ca}^{2+}$ because it was insensitive to BAPTA (Fig. 9C). We do not know why $\mathrm{I}_{\mathrm{Cl}(h)}$ was observed only in $\triangle$ MasIne-135-expressing oocytes rather than 108-rGAT1- or MasIne-135-expressing oocytes. Oocytes expressing 108-rGAT1 and $\Delta$ MasIne-135 died within $72 \mathrm{~h}$, in contrast to the 8-10 day survival time of MasIne-135expressing oocytes, and the resting membrane potential of these oocytes was close to $E_{\mathrm{Cl}}$, suggesting a constant release of intracellular $\mathrm{Ca}^{2+}$.

\section{Discussion}

We have cloned a Manduca sexta homologue of the inebriated gene from Drosophila melanogaster. MasIne and Drosophila Ine and RosA are highly homologous to the neurotransmitter transporter family of proteins. However, phylogenetic analysis (data not shown) shows that the inebriated proteins are divergent from other neurotransmitter transporters, suggesting that they have a common, yet distinct, function from that of the other transporters. We were able to express MasIne in the plasma membrane of Xenopus oocytes, but none of the ligands and/or substrates tested was transported.

A lack of transport could also result either because we failed to identify the correct substrate or because an additional protein may be required for transport. For example, LAT and $y^{+} \mathrm{LAT}$ amino acid transporters require an additional membranespanning protein, CD98, for amino acid uptake (Mastroberardino et al., 1998; Kanai et al., 1998; Torrents et al., 1998; Nakamura et al., 1999). However, our data show that inebriated is not a GABA or glutamate transporter, as proposed by Soehnge et al. (1996). Indeed, these transporters have been cloned and are distinct proteins (Mbungu et al., 1995; Donly et al., 1997).

Nevertheless, oocytes expressing MasIne displayed ligandindependent leakage conductances to alkali ions, suggesting that MasIne shares this property with other transporters. However, $\mathrm{Na}^{+}$-coupled, ligand-independent transient currents, which are often seen with other neurotransmitter transporters (Mager et al., 1993, 1994; Bossi et al., 1999), were not observed.

Although ligand transport was not observed in Xenopus oocytes with the substrates analyzed, MasIne responded to hyperosmotic stimulation by modulating the activation of outward $\mathrm{Cl}^{-}$currents. Using pharmacological agents, we showed that these $\mathrm{Cl}^{-}$currents were dependent on the release of intracellular $\mathrm{Ca}^{2+}$ through a PLC and $\mathrm{InsP}_{3}$ signaling pathway. Moreover, the current observed, $\mathrm{I}_{\mathrm{Cl}(\mathrm{Ca})}$, displayed a voltage- and time-dependence similar to those induced by $\mathrm{InsP}_{3}$ injection of oocytes (Hartzell, 1996). This hyperosmoticsensitive $\mathrm{Cl}^{-}$current was observed in Xenopus oocytes when the full-length MasIne protein, MasIne-135, was expressed. No $\mathrm{Cl}^{-}$currents were observed with expression of MasIne-459 or with the GABA and serotonin transporters during hyperosmotic stimulation.
Expression of a fusion protein consisting of the MasIne-135 $\mathrm{N}$ terminus with rGAT1 resulted in spontaneous activation of $\mathrm{I} \mathrm{Cl}(\mathrm{Ca})$, even without hyperosmotic stimulation. These currents were also observed when the $\mathrm{N}$ terminus alone was expressed in oocytes without osmotic stimulation. These data suggest that the N-terminal 108 amino acid residues of MasIne modulate PLC activation.

Since the $\mathrm{N}$ terminus spontaneously activated the endogenous currents, the data indicate that, when the fulllength protein is expressed, the $\mathrm{N}$ terminus interacts with other MasIne domains and, therefore, is unable to activate these currents. Hyperosmotic stimulation releases this $\mathrm{N}$ terminus, leading to PLC activation. In contrast, both 108-rGAT1 and $\Delta$ MasIne-135 lack this 'negative regulator' so that spontaneous activation of PLC occurs. Moreover, water-injected oocytes can also respond to hyperosmotic stimulation, but this response is significantly delayed (by more than $1 \mathrm{~min}$ ) and at occurs much higher osmolarities (approximately 300 mosmoll $^{-1}$ greater than those evoking equal responses in MasIneexpressing oocytes). This observation indicates that oocytes contain an endogenous hyperosmotic-responsive system that activates $\mathrm{I}_{\mathrm{Cl}(\mathrm{Ca}) \text {. }}$

Although none of the compounds analyzed was transported, we speculate that MasIne is a transporter. The transport of an unknown ligand, which could be an osmolyte, may cause activation of the $\mathrm{PLC} / \mathrm{InsP}_{3}$ cascade. This activation, dependent on the MasIne $\mathrm{N}$ terminus, is apparently not mediated through a G-protein, since GDP- $\beta$-S had no effect on the response observed. Furthermore, since this $\mathrm{N}$ terminus has no homology with either $\mathrm{G}_{\alpha}$ or protein tyrosine kinases, both known PLC activators, it appears that PLC activation is mediated through a novel mechanism. Activation of the $\mathrm{PLC} / \mathrm{InsP}_{3}$ cascade leads to increases in intracellular $\mathrm{Ca}^{2+}$ concentrations, which can then stimulate $\mathrm{Ca}^{2+}$-activated channels, including those that transport $\mathrm{K}^{+}$.

The inebriated protein is expressed in nearly identical tissue patterns in the nervous and muscular systems of both Manduca sexta and Drosophila melanogaster. However, differences in the expression patterns are observed in the gut, perhaps reflecting dietary differences between the two insect species. Manduca sexta larvae feed on a diet high in $\mathrm{K}^{+}$, which is used for nutrient transport in the midgut. To maintain homeostasis, $\mathrm{K}^{+}$in the hemolymph is transported into the midgut by a coupled $\mathrm{K}^{+} / 2 \mathrm{H}^{+}$transport system (Harvey, 1992; Wieczorek et al., 1999). In the midgut, the V-ATPase in goblet cell apical membranes pumps $\mathrm{H}^{+}$from the cytoplasm into the goblet cell cavity. The protons are exchanged with $\mathrm{K}^{+}$by a $\mathrm{K}^{+} / 2 \mathrm{H}^{+}$ exchanger, resulting in net $\mathrm{K}^{+}$transport from the goblet cell into the midgut. Both passive and active $\mathrm{K}^{+}$transport processes are present in the goblet cell basolateral membrane (Chao et al., 1990; Moffett et al., 1982; Moffett and Lewis, 1990; Zeiske et al., 1986), indicating that several mechanisms of $\mathrm{K}^{+}$ transport exist in this membrane. We speculate that MasIne, localized entirely in the basolateral membrane of goblet cells, may play a role in $\mathrm{K}^{+}$transport from the hemolymph into the goblet cells. 
In lepidopteran insects, such as Manduca sexta, the Malpighian tubules, ileum, rectum and cryptonephridial system, a sac-like structure that packs Malpighian tubules tightly with the rectal epithelium, are all involved in the maintenance of salt and water balance in the hemolymph (Ramsay, 1976). In these tissues, MasIne is expressed at high levels only in regions involved in ion reabsorption (Phillips, 1981; Ramsay, 1976). The middle region of Malpighian tubules is not specialized for ion reabsorption, and MasIne expression in this region is very low.

The glial cell layer and its processes form a blood-brain barrier around the neurons and neuropil, which constantly secretes $\mathrm{Na}^{+}$and absorbs $\mathrm{K}^{+}$(Schofield, 1989; Treherne and Schofield, 1981), so that high hemolymph $\mathrm{K}^{+}$levels do not affect neuronal function. Potentially, MasIne in glial cells may regulate $\mathrm{K}^{+}$absorption. MasIne expression in the axonal plasma membrane suggests that it could also modulate neuronal excitability by stimulating $\mathrm{Ca}^{2+}$-sensitive channels that cause membrane repolarization (Stern and Ganetzky, 1992).

This is the first report demonstrating the involvement of the PLC/InsP $P_{3}$ signaling cascade in a member of the $\mathrm{Na}^{+} / \mathrm{Cl}^{-}$dependent neurotransmitter transporter family. The mechanisms by which these processes are modulated are not known, and additional studies are needed to define the mechanisms involved more fully.

We thank M. E. Adams, C. Y. Lytle, M. J. Schuler, D. Zitnan, A. K. Pullikuth, C. Labarca, M. Filippova, A. Kondo and L. McCloud for helpful discussion and technical support. This research was supported by grants from the NIH (AI 34524 and AI48049 to S.S.G. and DA-09121 to H.A.L.).

\section{References}

Ackerman, M. J., Wickman, K. D. and Clapham, D. E. (1994). Hypotonicity activates a native chloride current in Xenopus oocytes. J. Gen. Physiol. 103, 153-179.

Bossi, E., Centinaio, E., Castagna, M., Giovannardi, S., Vincenti, S., Sacchi, V. F. and Peres, A. (1999). Ion binding and permeation through the lepidopteran amino acid transporter KAAT1 expressed in Xenopus oocytes. J. Physiol., Lond. 515, 729-742.

Bruss, M., Hammermann, R., Brimijoin, S. and Bonisch, $\mathbf{H}$. (1995). Antipeptide antibodies confirm the topology of the human norepinephrine transporter. J. Biol. Chem. 270, 9197-9201.

Burg, M. G., Geng, C. X., Guan, Y. H., Koliantz, G. and Pak, W. L. (1996). Drosophila rosA gene, which when mutant causes aberrant photoreceptor oscillation, encodes a novel neurotransmitter transporter homologue. J. Neurogenet. 11, 59-79.

Chao, A. C., Koch, A. R. and Moffett, D. F. (1990). Basal membrane uptake in potassium-secreting cells of midgut of tobacco hornworm Manduca sexta. Am. J. Physiol. 258, R112-R119.

Donly, B. C., Richman, A., Hawkins, E., McLean, H. and Caveney, S. (1997). Molecular cloning and functional expression of an insect high-affinity $\mathrm{Na}^{+}$-dependent glutamate transporter. Eur. J. Biochem. 248, 535-542.

Ganetzky, B. and Wu, C. F. (1983). Neurogenetic analysis of potassium currents in Drosophila: synergistic effects on neuromuscular transmission in double mutants. J. Neurogenet. $\mathbf{1}$, 17-28.

Guastella, J., Nelson, N., Nelson, H., Czyzyk, L., Keynan, S., Miedel, M. C., Davidson, N., Lester, H. A. and Kanner, B. I. (1990). Cloning and expression of a rat brain GABA transporter. Science 249, 1303-1306.

Hartzell, H. C. (1996). Activation of different $\mathrm{Cl}$ currents in Xenopus oocytes by $\mathrm{Ca}$ liberated from stores and by capacitative $\mathrm{Ca}$ influx. J. Gen. Physiol. 108, 157-175.

Harvey, W. R. (1992). Physiology of V-ATPases. J. Exp. Biol. 172, $1-17$.

Jobling, S. A. and Gehrke, L. (1987). Enhanced translation of chimaeric messenger RNAs containing a plant viral untranslated leader sequence. Nature 325, 622-625.

Kanai, Y., Segawa, H., Miyamoto, K., Uchino, H., Takeda, E. and Endou, H. (1998). Expression cloning and characterization of a transporter for large neutral amino acids activated by the heavy chain of 4F2 antigen (CD98). J. Biol. Chem. 273, 23629-23632.

Kowdley, G. C., Ackerman, S. J., John, J. E., Jones, L. R. and Moorman, J. R. (1994). Hyperpolarization-activated chloride currents in Xenopus oocytes. J. Gen. Physiol. 103, 217-230.

Kozak, M. (1987). An analysis of 5'-noncoding sequences from 699 vertebrate messenger RNAs. Nucleic Acids Res. 15, 8125-8148.

Kuruma, A. and Hartzell, H. C. (1999). Dynamics of calcium regulation of chloride currents in Xenopus oocytes. Am. J. Physiol. 45, C161-C175.

Mager, S., Kleinberger-Doron, N., Keshet, G. I., Davidson, N., Kanner, B. I. and Lester, H. A. (1996). Ion binding and permeation at the GABA transporter GAT1. J. Neurosci. 16, 5405-5414.

Mager, S., Min, C., Henry, D. J., Chavkin, C., Hoffman, B. J., Davidson, N. and Lester, H. A. (1994). Conducting states of a mammalian serotonin transporter. Neuron 12, 845-859.

Mager, S., Naeve, J., Quick, M., Labarca, C., Davidson, N. and Lester, H. A. (1993). Steady-states, charge movements and rates for a cloned GABA transporter expressed in Xenopus oocytes. Neuron 10, 177-188.

Mastroberardino, L., Spindler, B., Pfeiffer, R., Skelly, P. J., Loffing, J., Shoemaker, C. B. and Verrey, F. (1998). Amino-acid transport by heterodimers of $4 \mathrm{~F} 2 \mathrm{hc} / \mathrm{CD} 98$ and members of a permease family. Nature 395, 288-291.

Mbungu, D., Ross, L. S. and Gill, S. S. (1995). Cloning, functional expression and pharmacology of a GABA transporter from Manduca sexta. Arch. Biochem. Biophys. 318, 489-497.

Moffett, D. F., Hudson, R. L., Moffett, S. B. and Ridgway, R. L. (1982). Intracellular $\mathrm{K}^{+}$activities and cell-membrane potentials in a $\mathrm{K}^{+}$-transporting epithelium, the midgut of tobacco hornworm Manduca sexta. J. Membr. Biol. 70, 59-68.

Moffett, D. F. and Lewis, S. A. (1990). Cation channels of insect midgut goblet cells: conductance diversity and $\mathrm{Ba}^{+2}$ activation. Biophys. J. 57, 85a.

Nakamura, E., Sato, M., Yang, H. L., Miyagawa, F., Harasaki, M., Tomita, K., Matsuoka, S., Noma, A., Iwai, K. and Minato, N. (1999). 4F2 (CD98) heavy chain is associated covalently with an amino acid transporter and controls intracellular trafficking and membrane topology of 4F2 heterodimer. J. Biol. Chem. 274, 3009-3016.

Nowak, M. W., Gallivan, J. P., Silverman, S. K., Labarca, C. G., Dougherty, D. A. and Lester, H. A. (1998). In vivo incorporation 


\section{C.-S. CHIU AND OTHERS}

of unnatural amino acids into ion channels in Xenopus oocyte expression system. Meth. Enzymol. 293, 504-529.

Parker, I. and Miledi, R. (1988). A calcium-independent chloride current activated by hyperpolarization in Xenopus oocytes. Proc. $R$. Soc. Lond. B 233, 191-199.

Phillips, J. (1981). Comparative physiology of insect renal function. Am. J. Physiol. 241, R241-R257.

Pralong-Zamofing, D., Yi, Q. H., Schmalzing, G., Good, P. and Geering, K. (1992). Regulation of alpha 1-beta 3-Na+- $\mathrm{K}^{+}$-ATPase isozyme during meiotic maturation of Xenopus laevis oocytes. Am. J. Physiol. 262, C1520-C1530.

Pringle, J. R., Adams, A. E., Drubin, D. G. and Haarer, B. K. (1991). Immunofluorescence methods for yeast. Meth. Enzymol. 194, 565-602.

Ramsay, J. A. (1976). The rectal complex in the larvae of Lepidoptera. Phil. Trans. R. Soc. Lond. B 274, 203-226.

Ross, L. R. and Gill, S. S. (1996). Limited growth PCR screening of a plasmid library. Biotechniques 21, 382-386.

Schofield, P. K. (1989). Electrical charge properties of connective tissue in the insect central nervous system, with regard to ionic homeostasis of the nerve cell environment. Symp. Soc. Exp. Biol. 43, 379-388.

Shafqat, S., Velaz-Faircloth, M., Guadano-Ferraz, A. and Fremeau, R. T. J. (1993). Molecular characterization of neurotransmitter transporters. Mol. Endocr. 7, 1517-1529.

Soehnge, H., Huang, X., Becker, M., Whitley, P., Conover, D. and Stern, M. (1996). A neurotransmitter transporter encoded by the Drosophila inebriated gene. Proc. Natl. Acad. Sci. USA 93, 13262-13267.

Sonders, M. S., Zhu, S. J., Zahniser, N. R., Kavanaugh, M. P. and Amara, S. G. (1997). Multiple ionic conductances of the human dopamine transporter: The actions of dopamine and psychostimulants. J. Neurosci. 17, 960-974.

Stern, M. and Ganetzky, B. (1992). Identification and characterization of inebriated, a gene affecting neuronal excitability in Drosophila. J. Neurogenet. 8, 157-172.

Stern, M., Kreber, R. and Ganetzky, B. (1990). Dosage effects of a Drosophila sodium channel gene on behavior and axonal excitability. Genetics 124, 133-143.

Tokimasa, T. and North, R. A. (1996). Effects of barium, lanthanum and gadolinium on endogenous chloride and potassium currents in Xenopus oocytes. J. Physiol., Lond. 496, 677-686.

Torrents, D., Estevez, R., Pineda, M., Fernandez, E., Lloberas, J., Shi, Y. B., Zorzano, A. and Palacin, M. (1998). Identification and characterization of a membrane protein $\left(\mathrm{y}^{+} \mathrm{L}\right.$ amino acid transporter-1) that associates with $4 \mathrm{~F} 2 \mathrm{hc}$ to encode the amino acid transport activity $\mathrm{y}^{+} \mathrm{L}-\mathrm{A}$ candidate gene for lysinuric protein intolerance. J. Biol. Chem. 273, 32437-32445.

Treherne, J. E. and Schofield, P. K. (1981). Mechanisms of ionic homeostasis in the central nervous system of an insect. J. Exp. Biol. 95, 61-73.

Vassilakos, A., Hughes, M. J. and Andrews, D. W. (1995). The 3' untranslated region of bovine preprolactin contains a transferable non-poly(A) mRNA sequence that prolongs translation. FEBS Lett. 359, 206-210.

Wieczorek, H., Gruber, G., Harvey, W. R., Huss, M. and Merzendorfer, H. (1999). The plasma membrane $\mathrm{H}^{+}-\mathrm{V}-\mathrm{ATPase}$ from tobacco hornworm midgut. J. Bioenerg. Biomembr. 31, $67-74$.

Zeiske, W., Van Driessche, W. and Ziegler, R. (1986). Current-noise analysis of the basolateral route for $\mathrm{K}^{+}$ions across a $\mathrm{K}^{+}$-secreting insect midgut epithelium Manduca sexta. Pflügers Arch. 407, 657-663.

Zitnan, D., Ross, L. S., Zitnanova, I., Hermesman, J. L., Gill, S. S. and Adams, M. E. (1999). Steroid induction of a peptide hormone gene leads to orchestration of a defined behavioral sequence. Neuron 23, 523-535. 